\title{
Meteorological Characteristics and Dust Distribution of the Tarim Basin Simulated by the Nesting RAMS/CFORS Dust Model
}

\author{
Itsushi UNO \\ Research Institute for Applied Mechanics, Kyushu University, Kasuga, Fukuoka, Japan \\ Kazuhiro HARADA, Shinsuke SATAKE, Yukari HARA \\ Earth System Science and Technology, Kyushu University, Kasuga, Fukuoka, Japan \\ and \\ Zifa WANG \\ Institute of Atmospheric Physics, CAS, Beijing, China \\ (Manuscript received 30 August 2004, in final form 4 February 2005)
}

\begin{abstract}
A nested regional meteorology/dust-transport model was applied to an Asian region including the Taklimakan Desert. A three-grid system with a resolution of $81 \mathrm{~km}, 27 \mathrm{~km}$ and $9 \mathrm{~km}$ was designed and model calculation was conducted over the whole period of April 2001 to examine the typical springtime meteorology and some dust episodes over the Taklimakan Desert region. The performance model was examined based on meteorological observation at WMO SYNOP station surrounding the Taklimakan Desert and ADEC special observation site at Qira. The model results reproduced complicated airflows within the Tarim Basin, strong down slope winds from the Tianshan Mountains when meteorological disturbances crosses over the Taklimakan region, and a strong easterly flow from the Hexi Corridor side. Composite analysis when the Tazhong site simulated an easterly wind was conducted and showed that the percentage of the occurrence of this condition was approximately $50 \%$ of the full simulation period. The scale of the easterly wind zone is $400 \mathrm{~km}$ in the $\mathrm{Y}$ direction, $1000 \mathrm{~km}$ in the $\mathrm{X}$ direction and $2-3 \mathrm{~km}$ vertically. Simulated high dust concentration shows a good correlation with this easterly wind zone. The model's averaged dust concentration fields showed that the surface concentration ratio was approximately 0.6 between the eastern and western side of the Tarim Basin. However, the modeled ratio showed an opposite relation with the SYNOP visibility, thereby indicating that the current high wind type dust emission scheme may be insufficient to simulate the suspended dust phenomena in the western part of the Tarim Basin.
\end{abstract}

\section{Introduction}

Asian dust has two vast sources-the Taklimakan and Gobi Deserts (see Fig. 1). That dust

Corresponding author: Itsushi Uno, Research Institute for Applied Mechanics, Kyushu University, Kasuga Park 6-1, Kasuga, 816-8580, Fukuoka, JAPAN.

E-mail: iuno@riam.kyushu-u.ac.jp

(C) 2005, Meteorological Society of Japan has a strong impact on Asian air quality and atmospheric radiation. Most of the dust observation and modeling research efforts are devoted to dust from the Gobi because the Gobi Desert is located near large urban areas such as Beijing, Seoul, and Japan (e.g., Park and In 2003; Gong et al. 2003; Uno et al. 2001; Wang et al. 2000). The Taklimakan Desert is located in the Tarim Basin, which is surrounded by high mountains (including the Pamir Plateau, 
Tibetan Plateau, the Tian Shan Mountains, and the Kunlun Mountains). Dust from the desert is inferred to be trapped within the Tarim Basin. Furthermore, the horizontal size of the Taklimakan Desert is ca. $1400 \mathrm{~km}$ in the east-west direction and $550 \mathrm{~km}$ in the southnorth direction with a limited number of observation points, which are all located in oasis cities at the edge of the desert area (see Fig. 1c). Consequently, it is hard to capture detailed information regarding the central part of the Taklimakan Desert. Recently, the Taklimakan dust is believed to have a strong impact on Asian air quality (Iwasaka et al. 2003; Uno et al. 2004). Nevertheless, detailed studies of its behavior are quite limited. Further observation and examination of the Taklimakan Desert are required (Shao and Wang 2003).

Mikami et al. (1995), Mikami (1997), and Kurosaki and Mikami (2002) showed results of basic meteorological analysis and seasonal and regional characteristics of dust events. Sun et al. (2001) presented a classification of typical dust transport routes based on a 40-year dust storm report and the unique characteristics of the Taklimakan dust transport. Kai et al. (1988) simulated a case study of Taklimakan dust transport based on the Lagrangian particle model and indicated the impact of Taklimakan dust in areas in Japan. However, the local wind circulation and its 3D structure over the Tarim Basin have not been well studied. One pioneering study was undertaken by Aoki (2003); he elucidated the meteorological conditions that bring about the dust storms in the Tarim Basin using the SYNOP report, NCEP reanalysis, and a regional meteorological model. Based on springtime analyses for 19982001, that study classified the meteorological conditions into three categories: the Tian Shan Mountain detour pattern, the Tian Shan Mountain pass-over pattern, and the Pamir Plateau pass-over pattern. These patterns are important for understanding the meteorological conditions that create heavy dust storms in the Tarim Basin. Several mesoscale model simulations were reported for each pattern, but the simulation period was only 3-4 days for each case and the average flow structure, which was important for the dust phenomena, could not be described. Because of this area's very complicated topography, high-resolution numerical mesoscale meteorological modeling is required. However, such work is computationally expensive and quite limited.

The Aeolian Dust Experiment impact on Climate (ADEC) was begun in April 2000. As described by Mikami et al. (2002), the ADEC project set up a network observation of the Taklimakan dust including dust emission, transport and deposition. Using that network, the project provided observational and numerical data regarding Asian dust phenomena. As part of this ADEC study, we extended a version of RAMS/CFORS regional meteorology and dustemission/transport model (Uno et al. 2003) to provide multiple nesting capabilities. A triplenested grid system with $81 \mathrm{~km}, 27 \mathrm{~km}$ and $9 \mathrm{~km}$ resolutions was used to cover the detailed topography, soil texture, and land use type over the Taklimakan and Gobi Desert areas. The dust episode during April 2001 was simulated with the three-grid nested RAMS/CFORS system. The period of April 2001 was selected because five dust storms were reported in the analysis of Aoki (2003). The structure of this paper is as follows. Section 2 briefly describes the nesting RAMS/CFORS meteorology/dust model. Section 3 presents an outline of the observation data used in this work. Section 4 shows results of model analysis. First in Sections 4.1 and 4.2 , the modeled meteorology is examined intensively and the capability of model simulation with the WMO SYNOP surface weather report (wind speed and direction and visibility) and ADEC Automatic Weather Station (AWS) observation at the Qira site (Mikami et al. 2004) are shown. In Section 4.3, analysis of a detailed case during a very strong cold-air outbreak is studied based on the synoptic scale $500 \mathrm{hPa}$ level and RAMS results. In Section 4.4, composite studies are conducted to show the average meteorological structure of easterly wind conditions. We will also show the average dust concentration and the horizontal and vertical gradient of the potential temperature within the Tarim Basin. In Section 4.5, we will examine the average dust concentration field between the eastern and western parts of the Taklimakan Desert and indicate the importance of the different mechanisms of suspended dust in the western part of the Taklimakan Desert. Finally, conclusions of this study are summarized in Section 5. 


\section{Dust model descriptions}

CFORS (Uno et al. 2003) was designed as a multi-tracer using an on-line system built within the Regional Atmospheric Modeling System (RAMS) (Pielke et al. 1992; Cotton et al. 2003). RAMS has a multiple nesting capability, but the original CFORS is designed as a single grid system. Therefore we carefully extended it to a multiple nesting system. Note that tracers in CFORS run on-line in RAMS. Consequently, all of the multiple nesting meteorological information from RAMS is used in CFORS dust transport modules.

The CFORS system treats size-resolved mineral dust using 12 particle-size bins. The 12 radial size ranges are $0.1-0.16,0.16-0.25$, $0.25-0.40, \quad 0.40-0.63, \quad 0.63-1.00, \quad 1.00-1.58$, $1.58-2.51, \quad 2.51-3.98, \quad 3.98-6.31,6.31-10.0$, $10.0-15.85$, and $15.85-25.12 \mu \mathrm{m}$. The mass distribution varies linearly with respect to ra$\operatorname{dius}(r<1.0 \mu \mathrm{m})$ and $\log$ (radius) $(r>1.0 \mu \mathrm{m})$. Mineral aerosols are emitted into the atmosphere as a result of high surface winds. In CFORS, the total dust uplift flux, $F_{\text {dust }}(\mathrm{kg} /$ $\mathrm{m}^{2} / \mathrm{s}$ ), is calculated on-line using a fourth power-law function of the surface friction velocity $u_{*}$. The initial dust uplift height (i.e., the injection height) is very uncertain. In the CFORS dust module, the mixing height $Z_{B L}$ is diagnosed from the vertical potential temperature profile (from RAMS). The uplifted dust mass-mixing ratio is distributed uniformly within the $Z_{B L}$; with this pre-mixing treatment, $Z_{B L}$ is diagnosed mainly below $1000-1500 \mathrm{~m}$ in height, which is still considered within the boundary layer. Within CFORS, natural dust emission areas are defined as desert and semidesert areas from the dataset of $1 \mathrm{~km}$ resolution land-cover characteristics produced by the U.S. Geological Survey (USGS) based on Advanced Very High Resolution Radiometer (AVHRR) data obtained in 1992-1993. The specification of $u_{*, t h}$ is important for determining dust emission flux. Food and Agriculture Organization (FAO) soil texture information is used to estimate the critical threshold friction velocity $\left(u_{*, t h}\right)$ for dust emission. Almost no information is available regarding the exact $u_{*, t h}$ within the Taklimakan Desert. For that reason, we used the value from Uno et al. (2003, 2004). We believe that our current specification is sufficient to simulate the semi-quantitative behavior of Taklimakan dust emissions. However, to obtain better agreement of absolute concentration level, the modeled dust emission scheme must be tuned based on the ground observation data.

Figure 1 shows the model domain. This study used a triple-nested grid system. The numerical model domain of Grid 1 is centered at $38.5^{\circ} \mathrm{N} 108^{\circ} \mathrm{E}$ on a rotated polar stereographic system. The horizontal grid comprises $87 \times 50$ grid points with a resolution of $81 \mathrm{~km}$. The model's vertical domain extends vertically from the surface to $20 \mathrm{~km}$ with 70 stretching grid layers varying from $150-\mathrm{m}$-thick at the surface to 300-m-thick at the top of domain.

Figure 1(b) shows the region of Grid 2 $(143 \times 59$ grid points $)$ with a resolution of $27 \mathrm{~km}$. Shaded information is that for the semidesert and desert regions. This model domain can simulate mineral dust emissions from both the Taklimakan and Gobi regions.

Figure 1(c) shows the region of Grid 3 $(188 \times 119$ grid points) with a resolution of $9 \mathrm{~km}$. The shaded tones represent the classification of FAO soil texture used in this study (FAO soil texture data is compliant with RAMS LEAF2 soil type classifications). Because of the polar stereographic coordinate system used, the actual north direction is not indicated as the upper direction of the map. Closed dots in this figure represent SYNOP weather stations used for model evaluation. The horizontal resolution of $9 \mathrm{~km}$ is necessary to resolve the size of oasis cities at the southern edge of the Taklimakan Desert.

RAMS/CFORS is a regional meteorological model that requires initial and boundary meteorological conditions. In this paper, the ECMWF reanalysis data with $1^{\circ} \times 1^{\circ}$ resolution (6-h interval at specified pressure levels of $1000,925,850,700,500,400,300,250,200$, $150,100,70,50,30$, and $10 \mathrm{hPa}$ ) was used for nudging (five outermost grids of Grid 1). CFORS was applied for the period of 29 March-30 April 2001 with weekly SST data; we also used observed monthly snow-cover data. Detailed RAMS options used in this work is shown in Table 1 and detailed grid specifications are listed in Table 2. More details of CFORS are described in Uno et al. $(2003,2004)$ and Satake et al. (2004). 
a) Region of Grid 1 (with elevation)

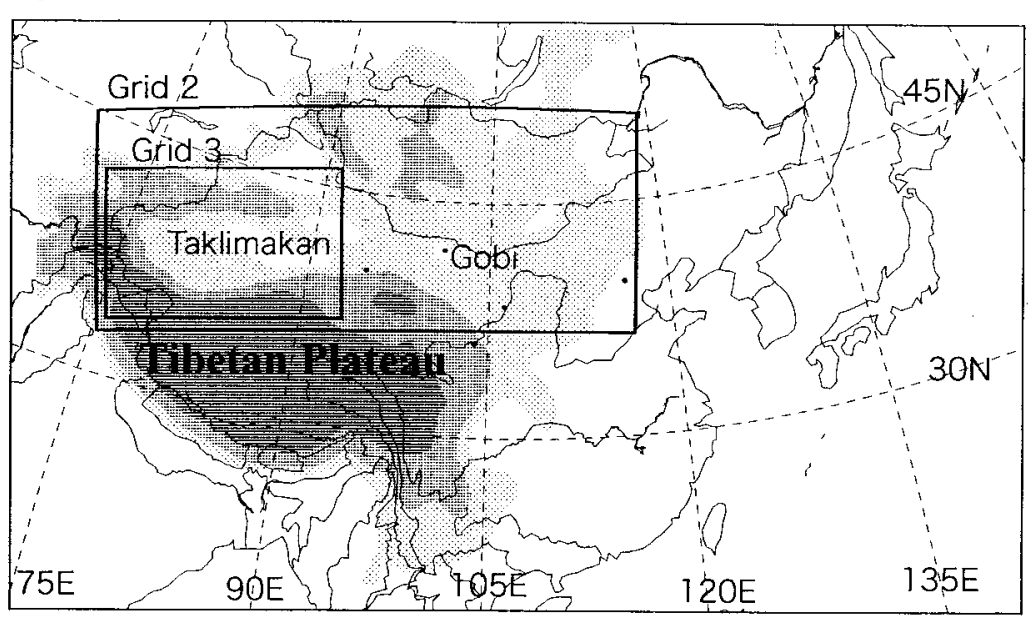

$z(m)$

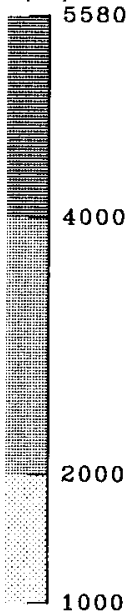

b) Region of Grid 2 (with desert/semi-desert distribution)
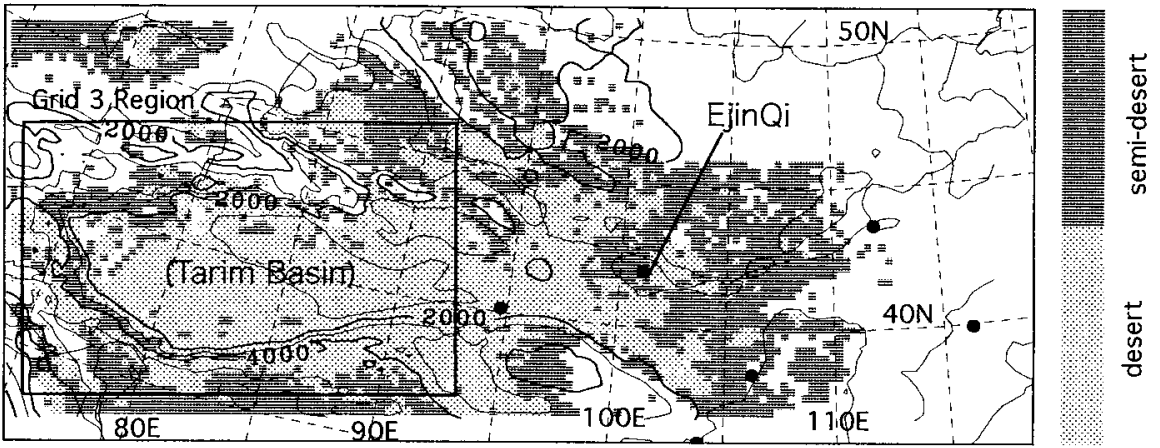

c) Region of Grid 3 (with soil texture)

soil texture
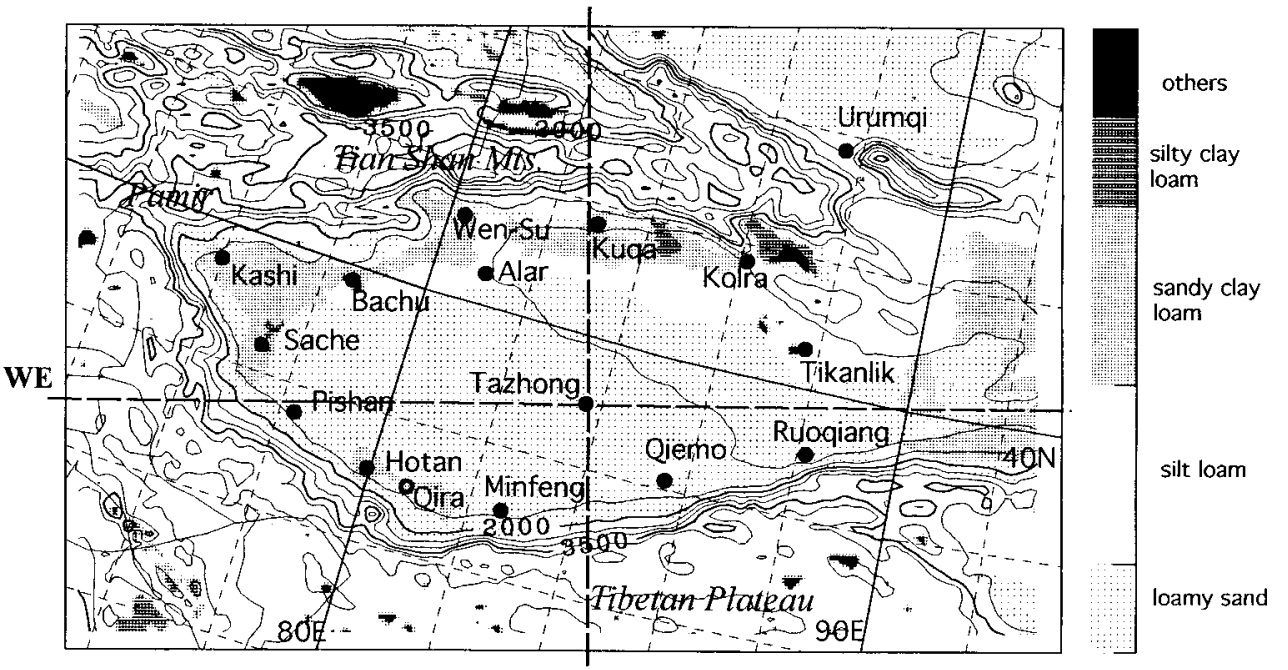

Fig. 1. Model domain. (a) Region of Grid 1 and topography, (b) Region of Grid 2 with the distribution of desert and semi-desert area, (c) Region of Grid 3 with soil texture distribution. Closed dots are the location of SYNOP observation sites and the open circle is the ADEC Qira site. Lines of NS and WE are inserted for Figs. 6 and 7. 
Table 1. Model Configuration

\begin{tabular}{|c|c|}
\hline $\begin{array}{l}\text { Basic } \\
\text { equation }\end{array}$ & Non-hydrostatic, compressible \\
\hline $\begin{array}{l}\text { Horizontal } \\
\text { Coordinate }\end{array}$ & Polar-Stereographic tangent plane \\
\hline $\begin{array}{l}\text { Vertical } \\
\text { coordinate }\end{array}$ & Terrain-following $z^{*}$ coordinate \\
\hline $\begin{array}{l}\text { Time } \\
\text { difference }\end{array}$ & Hybrid scheme \\
\hline $\begin{array}{l}\text { Cloud } \\
\text { Process }\end{array}$ & $\begin{array}{l}\text { Simplified Kuo Cumulus Scheme } \\
\text { \& Bulk Microphysics Cloud }\end{array}$ \\
\hline $\begin{array}{l}\text { Land } \\
\text { Surface } \\
\text { Model }\end{array}$ & LEAF-2 \\
\hline $\begin{array}{l}\text { Upper and } \\
\text { Lateral } \\
\text { Boundary } \\
\text { Condition }\end{array}$ & $\begin{array}{l}\text { Large Scale nudging with } \\
\text { ECMWF global analysis data } \\
\text { (Outer } 5 \text { Gird region of Grid } 1 \\
\text { only) }\end{array}$ \\
\hline $\begin{array}{l}\text { Atmospheric } \\
\text { Radiation }\end{array}$ & Chen and Cotton \\
\hline Turbulence & Mellor-Yamada Level 2.5 scheme \\
\hline Dust Scheme & $\begin{array}{l}12 \text { dust bins }(0.1-20.0 \mu \mathrm{m} \text { for } \\
\text { radii) (Uno et al. } 2003,2004)\end{array}$ \\
\hline
\end{tabular}

Table 2. Model Grid Configurations

\begin{tabular}{lccc}
\hline & Grid 1 & Grid 2 & Grid 3 \\
\hline $\begin{array}{c}\text { Center of } \\
\text { Domain }\end{array}$ & $\begin{array}{r}38.5^{\circ} \mathrm{N}, \\
108.0^{\circ} \mathrm{E}\end{array}$ & $\begin{array}{c}43.24^{\circ} \mathrm{N}, \\
94.07^{\circ} \mathrm{E}\end{array}$ & $\begin{array}{c}39.97^{\circ} \mathrm{N}, \\
82.76^{\circ} \mathrm{E}\end{array}$ \\
\hline $\begin{array}{l}\text { Horizontal } \\
\text { Resolution }\end{array}$ & $81 \mathrm{~km}$ & $27 \mathrm{~km}$ & $9 \mathrm{~km}$ \\
\hline $\begin{array}{l}\text { Horizontal } \\
\text { Gird }\end{array}$ & $87 \times 50$ & $143 \times 59$ & $188 \times 119$ \\
\hline $\begin{array}{l}\text { Vertical } \\
\text { Resolution }\end{array}$ & $150-300 \mathrm{~m}$ & $150-300 \mathrm{~m}$ & $150-300 \mathrm{~m}$ \\
\hline $\begin{array}{l}\text { Vertical } \\
\text { Grid }\end{array}$ & 70 & 70 & 70 \\
Levels & & & \\
\hline Time Step & $90 \mathrm{~s}$ & $30 \mathrm{~s}$ & $10 \mathrm{~s}$ \\
\hline
\end{tabular}

Liu et al. (2001) indicated clearly that the friction velocity (surface wind speed) strongly depends on the model resolution because the model topographical effect (blocking by high mountains and land use roughness effect) is highly sensitive for wind fields. For example, surface wind speed from Grid 1 is usually stronger than that from Grids 2 and 3 because of the former's smooth topography (Liu et al. 2001). However, in the Gobi region, the highresolution model gives a wide scatter in the grid point elevation and shows a large scatter in the friction velocity and sometimes gives more dust emission because of the non-linearity of friction velocity and dust emission. More detailed sensitivity analysis of the model resolution is presented in Liu et al. (2001). In this study, we widened the region of Grid 2 sufficiently to cover all of the Taklimakan and Gobi Desert. All dust emission flux was assigned from Grid 2 and Grid 3 because these regions covered all dust source areas of this study; there was no need to assign the dust emission from Grid 1.

\section{Observation data}

The number of observations within the Tarim Basin are quite limited. The most valuable observations are WMO SYNOP data (wind speed, wind direction, temperature, precipitation, visibility, etc.). SYNOP observation data were provided for 6 -h intervals. Figure 1c shows the SYNOP observation sites used in this paper. Note that wind speed was recorded with $1 \mathrm{~m} \mathrm{~s}^{-1}$ resolution. Table 3 shows the detailed location and elevation. The SYNOP site does not measure the dust concentration. Shao et al. (2003) found the following empirical relationships between visibility and dust concentration by fitting the near surface TSP (Total Suspended Particle) observations to visibility:

$C_{\mathrm{TSP}}=3802.29 D_{v}^{-0.85}$ for $D_{v}<3.5 \mathrm{~km}$

$C_{\mathrm{TSP}}=\exp \left(-0.11 D_{v}+7.62\right) \quad$ for $D_{v}>3.5 \mathrm{~km}$

where $C_{\mathrm{TSP}}$ is the dust concentration in micrograms per cubic meter and $D_{v}$ is the visibility in kilometers. This empirical equation gives a measure of dust concentration and dust onset timing. Note that $C_{\text {TSP }}$ is based on the empirical equation; for that reason, it is sometimes difficult to estimate the absolute concentration level.

Other important observation data were taken at the ADEC Qira site (Mikami et al. 2003). Figure 1(c) shows that Qira is located at the southern edge of the Tarim Basin between two oasis cities: Hotan and Minfeng. It is important 
Table 3. List of SYNOP observation stations and comparison of monthly averaged wind speed

\begin{tabular}{|c|c|c|c|c|c|c|c|}
\hline $\begin{array}{l}\text { Station } \\
\text { No. }\end{array}$ & $\begin{array}{l}\text { Station } \\
\text { Name }\end{array}$ & $\begin{array}{l}\text { Latitude } \\
\text { N }\end{array}$ & $\begin{array}{c}\text { Longitude } \\
\text { E }\end{array}$ & $\begin{array}{l}\text { Altitude } \\
\text { m (ASL) }\end{array}$ & $\begin{array}{l}\text { SYNOPa) } \\
\text { WS }(\mathrm{m} / \mathrm{s})\end{array}$ & $\begin{array}{l}\text { Exp-G3b) } \\
\text { WS (m/s) }\end{array}$ & $r^{c)}$ \\
\hline 51777 & Ruoqiang & $39^{\circ} 02^{\prime}$ & $88^{\circ} 10^{\prime}$ & 889 & 3.29 & 4.62 & 0.46 \\
\hline 51765 & Tikanlik & $40^{\circ} 38^{\prime}$ & $87^{\circ} 42^{\prime}$ & 847 & 2.16 & 4.57 & 0.47 \\
\hline 51656 & Kolra & $41^{\circ} 45^{\prime}$ & $86^{\circ} 08^{\prime}$ & 993 & 3.82 & 4.87 & 0.45 \\
\hline 51644 & Kuqa & $41^{\circ} 45^{\prime}$ & $82^{\circ} 57^{\prime}$ & 1100 & 3.00 & 4.83 & 0.40 \\
\hline 51628 & Wen-Su & $41^{\circ} 16^{\prime}$ & $80^{\circ} 14^{\prime}$ & 1286 & 2.19 & 3.39 & 0.36 \\
\hline 51730 & Alar & $40^{\circ} 30^{\prime}$ & $81^{\circ} 03^{\prime}$ & 1013 & 1.72 & 4.84 & $0.14^{*}$ \\
\hline 51716 & Bachu & $39^{\circ} 48^{\prime}$ & $78^{\circ} 34^{\prime}$ & 1117 & 2.46 & 4.12 & $0.19^{*}$ \\
\hline 51709 & Kashi & $39^{\circ} 28^{\prime}$ & $75^{\circ} 59^{\prime}$ & 1291 & 2.91 & 4.53 & 0.43 \\
\hline 51811 & Sache & $38^{\circ} 26^{\prime}$ & $77^{\circ} 16^{\prime}$ & 1232 & 2.10 & 4.49 & 0.40 \\
\hline 51818 & Pishan & $37^{\circ} 37^{\prime}$ & $78^{\circ} 17^{\prime}$ & 1375 & 1.84 & 4.47 & 0.24 \\
\hline 51828 & Hotan & $37^{\circ} 08^{\prime}$ & $79^{\circ} 56^{\prime}$ & 1375 & 2.23 & 4.25 & 0.37 \\
\hline 51839 & Minfeng & $38^{\circ} 09^{\prime}$ & $82^{\circ} 46^{\prime}$ & 1410 & 2.39 & 5.75 & 0.23 \\
\hline 51855 & Qiemo & $38^{\circ} 09^{\prime}$ & $85^{\circ} 33^{\prime}$ & 1248 & 1.42 & 4.78 & 0.26 \\
\hline 51747 & Tazhong & $39^{\circ} 00^{\prime}$ & $83^{\circ} 40^{\prime}$ & 1099 & 3.21 & 5.00 & 0.43 \\
\hline 51463 & Urumqi & $43^{\circ} 47^{\prime}$ & $87^{\circ} 37^{\prime}$ & 947 & 4.27 & 3.97 & 0.54 \\
\hline \multirow[t]{2}{*}{ ADEC } & Qira & $36^{\circ} 55^{\prime}$ & $80^{\circ} 48^{\prime}$ & 1380 & 4.65 & 4.95 & 0.48 \\
\hline & & & & Mean & 2.73 & 4.59 & \\
\hline \multicolumn{8}{|l|}{ Grid 2} \\
\hline 52267 & Ejin Qi & $41^{\circ} 57^{\prime}$ & $101^{\circ} 04^{\prime}$ & 941 & 4.55 & 5.91 & 0.71 \\
\hline
\end{tabular}

a) Monthly averaged observed wind speed at SYNOP station.

b) Monthly averaged RAMS/CFORS wind speed at $z=10 \mathrm{~m}$ from three grid nesting Experiment-G3.

c) Correlation coefficient between SYNOP stations of the model Experiment-G3. ' $r$ ' is calculated excluding the calm wind condition from SYNOP site. The symbol of * indicates that the correlation is not statistically significant under the $F$-test ( $5 \%$ level).

to point out that the ADEC Qira site is located in the desert, outside Qira. The present study used wind speed (WS), wind direction (WD), temperature $(\mathrm{T})$, and downward solar radiation (Rs) data. One hour averaged observation data was used for model comparison.

\section{Results and discussion}

This study conducted two model experiments: Experiment-G3-a control run with three grids nesting; and Experiment-G2-a sensitivity experiment using only two-grid nesting. This sensitivity experiment is intended to examine important meteorological conditions, which requires three-grid nesting (high-resolution sim- ulation). We will use results of these two experiments for detailed comparison with the observation data.

\subsection{Time-height cross-section of meteorology at Tazhong}

Figure 2 show RAMS model results of Tazhong SYNOP site from Experiment-G3 (Grid 3) simulation to provide a general overview of springtime meteorological conditions in the Tarim Basin. Figure 1c shows that Tazhong is located at the center of the Taklimakan Desert along the desert-crossing road; it is adequate to show the typical meteorological structure of the Tarim Basin. 
(a) Wind Speed ( $\mathrm{m} / \mathrm{s}$; line) and Direction (deg; tone)

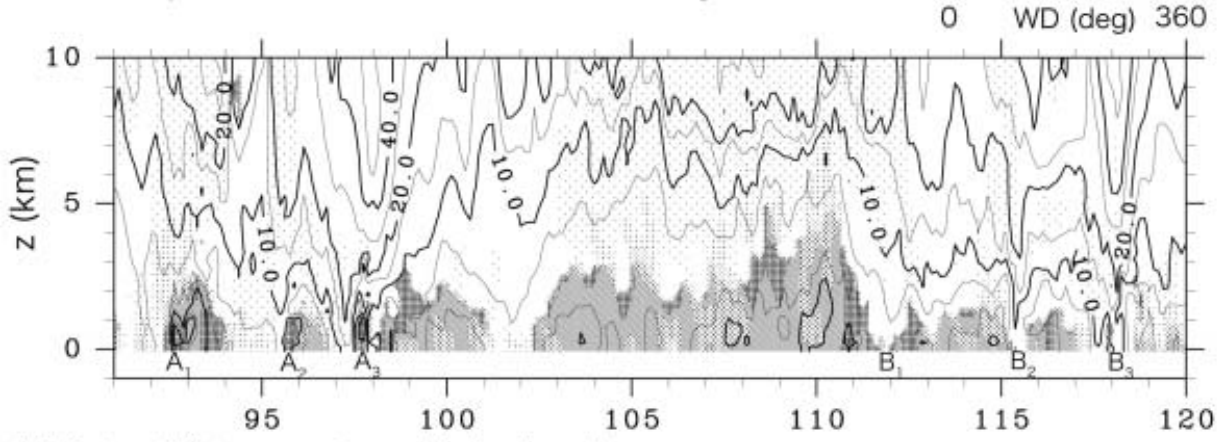

(b) Potential temperature ( $\mathrm{K}$; line) and specifc humidity, q ( $\mathrm{g} \mathrm{m}^{-3}$; tone)

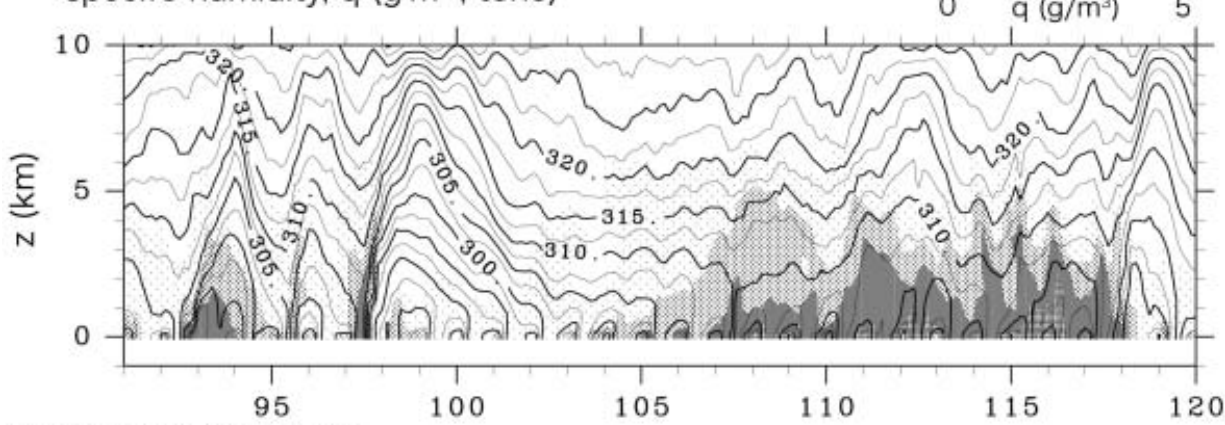

(c) Surface wind speed

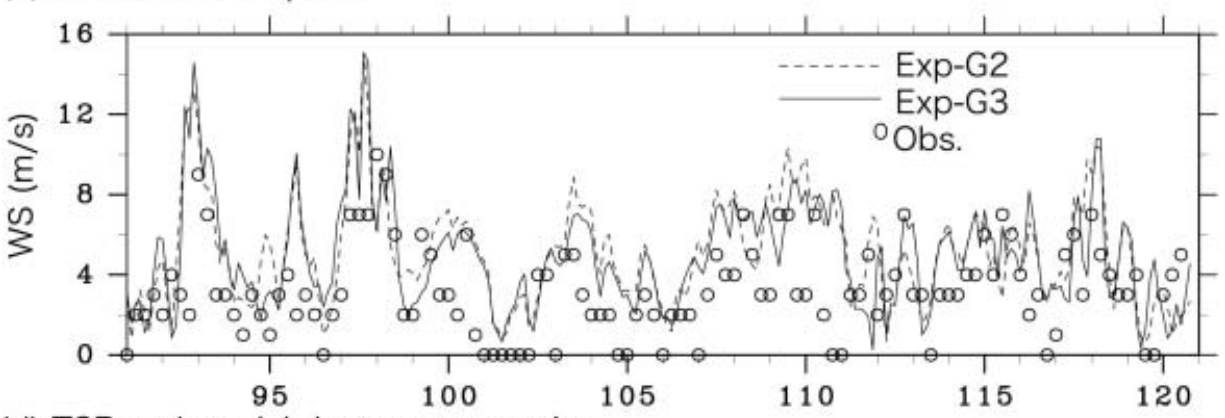

(d) TSP and model dust concentration

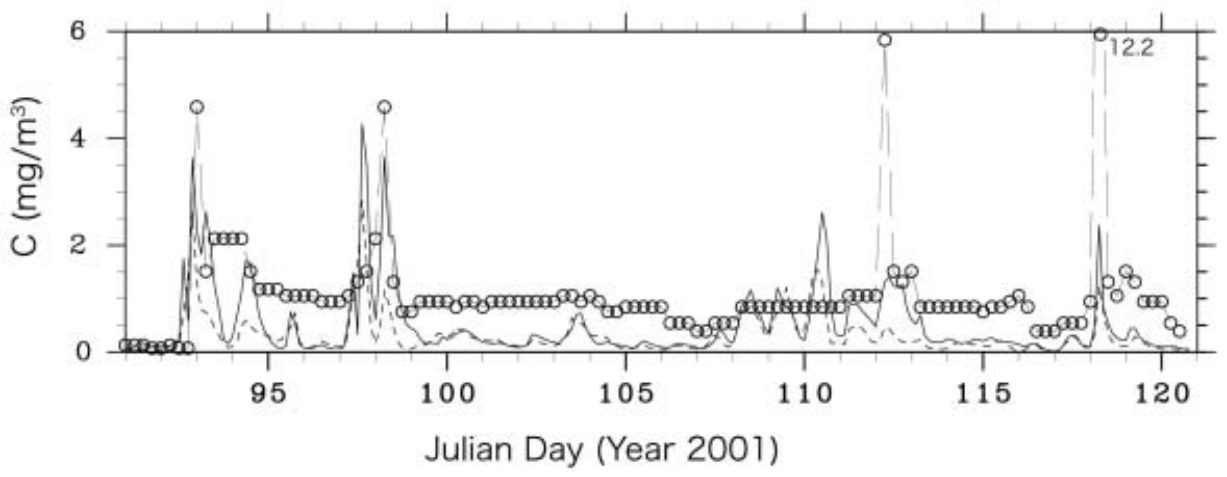

Fig. 2. RAMS model results from Experiment-G3 (Grid 3) simulated in Tazhong SYNOP site. (a) Time-height cross-section of WS (contour) and WD (tone), (b) time-height cross-section of potential temperature (contour) and specific humidity, $q$ (tone), (c) Comparison between SYNOP wind speed (circle) and RAMS wind speed at $z=10 \mathrm{~m}$ level, (d) Comparison between SYNOP $C_{\mathrm{TSP}}$ (circle connected by broken line) and CFORS total dust concentration. Solid line is from Experiment-G3 and dashed line is from Experiment-G2. 
Figure 2a shows the time-height crosssection of WS (contour) and WD (tone); Fig. 2b shows the potential temperature (contour) and specific humidity, $q$ (tone). Figure 2c compares the SYNOP wind speed (circle) and RAMS wind speed at the $z=10 \mathrm{~m}$ level. Herein, the wind speed at $10 \mathrm{~m}$ is calculated using MoninObukhov similarity. Figure $2 d$ compares the $C_{\mathrm{TSP}}$ (circle) and CFORS dust concentrations. In Figs. 2c and 2d, the straight line is taken from the model Experiment-G3 (Grid 3 nesting) and the dashed line from Experiment-G2 (Grid 2 nesting). Note that SYNOP observation has a 6 -h interval and that the model output is every $3 \mathrm{~h}$. In Fig. 2a, labels A and B are inserted when the model wind direction shows a strong northerly wind. The periods A and B correspond to the typical pattern of Tian Shan Mountain pass-over and Pamir Plateau passover, which are identified by Aoki (2003) and will be discussed in Section 4.3 as a case study.

From Fig. 2a, we can see that after the strong northerly wind $\left(\mathrm{A}_{1}, \mathrm{~A}_{2}, \mathrm{~A}_{3}, \mathrm{~B}_{1}, \mathrm{~B}_{2}\right.$, and $\mathrm{B}_{3}$ ), an easterly wind was simulated in Tazhong station. Thickness of this easterly wind was ca. $1000-2500 \mathrm{~m}$. Above this level, the average wind direction is northwest. At $\mathrm{A}_{3}$ and $B_{3}$, a very strong upper level wind reached the ground surface. Especially at $\mathrm{A}_{1}$ and $\mathrm{A}_{3}$, surface wind speed was greater than $10 \mathrm{~m} \mathrm{~s}^{-1}$. The RAMS wind speed differences between Experiment-G3 and -G2 are small: RAMS apparently captures the wind variation and its peak correctly (Fig. 2c). A comparison of averaged wind speed is also shown in Table 3.

During Julian days (hereafter Jdays) 102 and 110, the Tazhong site had an easterly wind. The synoptic condition during this period is different from those of periods of $\mathrm{A}$ and $\mathrm{B}$; no synoptic cold-front passed over the Taklimakan Desert.

Figure 2d shows that CFORS dust concentration reproduced the timing of the dust peak correctly despite several visible disagreements. The Tazhong site is located at the center of the Taklimakan Desert-it is completely surrounded by desert-and its base line of $C_{\mathrm{TSP}}$ concentration is around $0.7-1 \mathrm{mg} \mathrm{m}^{-3}$, which is extremely high. Therefore the effect of local dust plays an important role in the Tazhong visibility, which is not well reproduced by the dust transport model. We can see that dust concentration from Experiment-G3 is higher than that of Experiment-G2. Dust emission in the dust source region is inferred to be accumulated during the transport to the Tazhong site and caused concentration differences between the two sensitivity experiments. Especially, dust emission flux is proportional to the $3^{\text {rd }}$ (or $\left.4^{\text {th }}\right)$ power of the surface friction velocity, so even a small increase over the threshold velocity engenders a large difference in dust concentration. This fact indicates the necessity for a high-resolution model near the dust source region where the topography is very complex.

\subsection{Comparison of model wind speed and observation}

In this section, we will show a more detailed model comparison by separating the Tarim Basin into four regions: north (SYNOP station of Kuqa), west (Kashi), south (Minfeng) and east (Tikanlik) regions.

Figure 3 shows a comparison between SYNOP wind speed (symbols) and RAMS wind speed at $z=10 \mathrm{~m}$ levels for four regions of the Tarim Basin and one station from the Gobi Desert, Ejin Qi (located in Grid 2; see Fig. 1b). The straight line is taken from the model Experiment-G3 (up to Grid 3) and the dashed line is from Experiment-G2 (up to Grid 2). Note that SYNOP observations are recorded every $6 \mathrm{~h}$ and that the model output is every $3 \mathrm{~h}$.

Figure 4 shows the model comparison for the ADEC Qira site. It includes: (a) wind speed at $3 \mathrm{~m}$ height; (b) wind direction; (c) surface downward short-wave radiation, $R_{s}$; and (d) air temperature at $2 \mathrm{~m}$ height (model results were interpolated using Monin-Obukhov similarity). Observation data are taken from AWS (Mikami et al. 2004). The $R_{s}$ observation result is sensitive to sensor fouling with dirt, so the observed data are corrected based on an upward shortwave radiation assumed by the constant surface albedo (0.3).

Figures 3 and 4 show a RAMS wind field capturing the major strong wind events. Especially, RAMS reproduced strong wind peaks (Jdays 97-98 and 118) in the northern side of the Tarim Basin very well (Fig. 3a). The time duration of this strong wind is less than $12 \mathrm{~h}$. This wind was brought by the cold-air passover of the Tian Shan Mountains; after this 

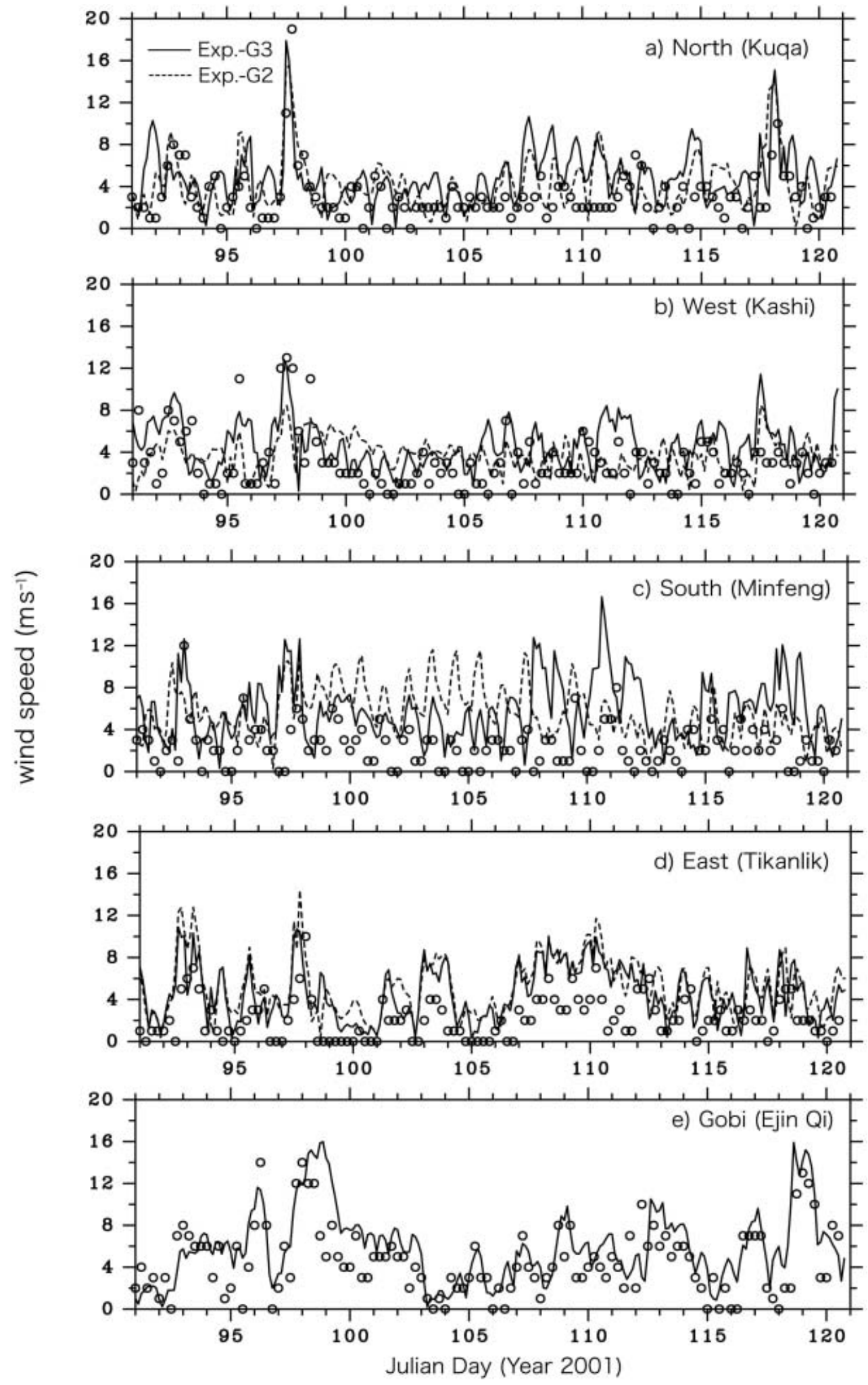

Fig. 3. Comparison between SYNOP wind speed (symbols) and RAMS wind speed at the $z=10 \mathrm{~m}$ level. Solid line is from Experiment-G3 and dashed line is from Experiment-G2. 
(a) Wind Speed $\left(\mathrm{ms}^{-1}\right)$

ADEC Qira Site

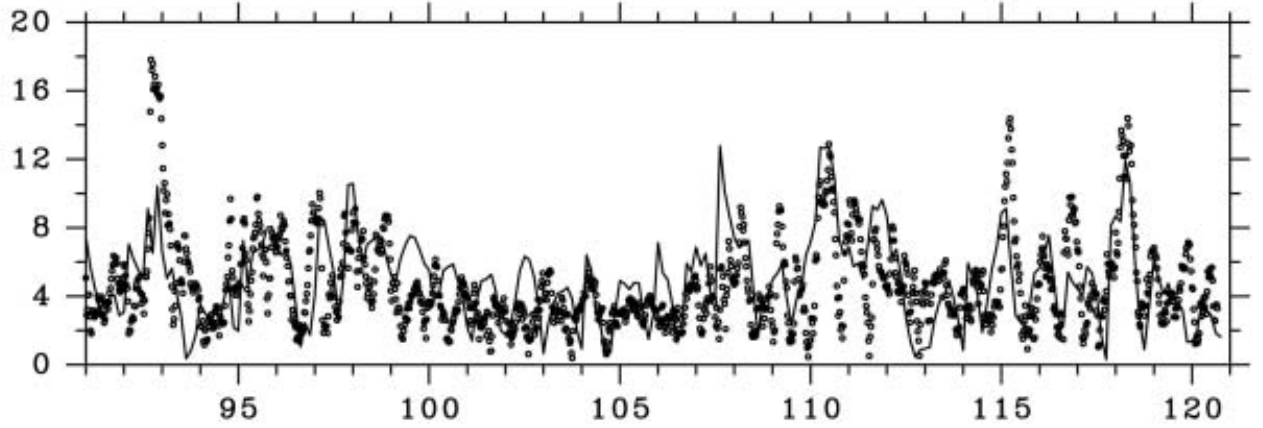

(b) Wind Direction (deg)

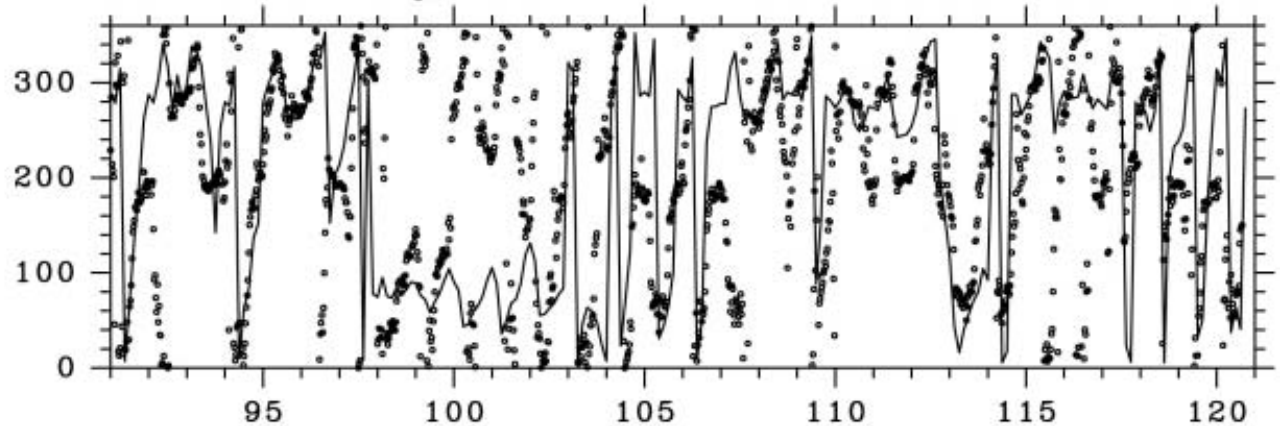

(c) Downward Short Wave Radiation (Watt $/ \mathrm{m}^{2}$ )

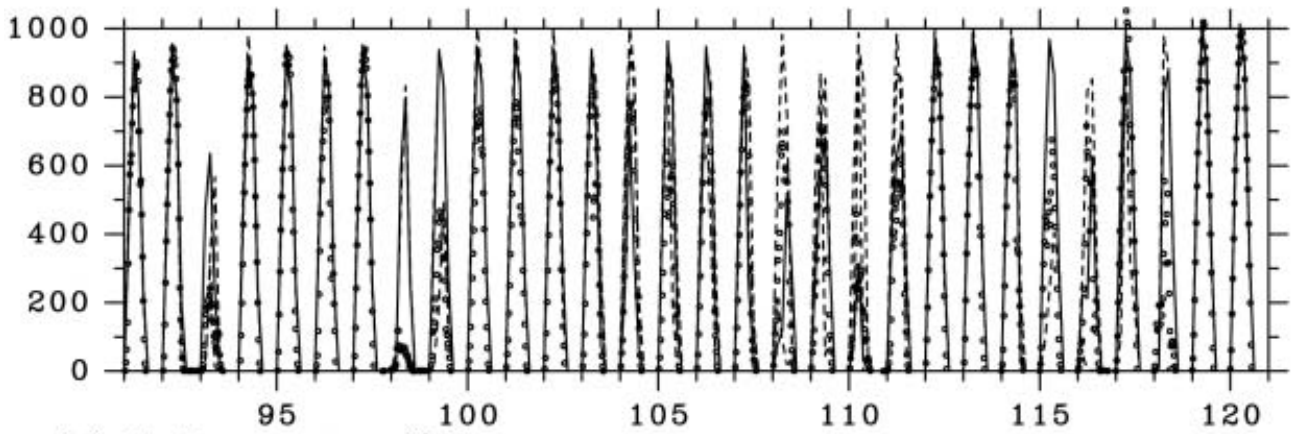

(d) Air Temperature $\left({ }^{\circ} \mathrm{C}\right)$

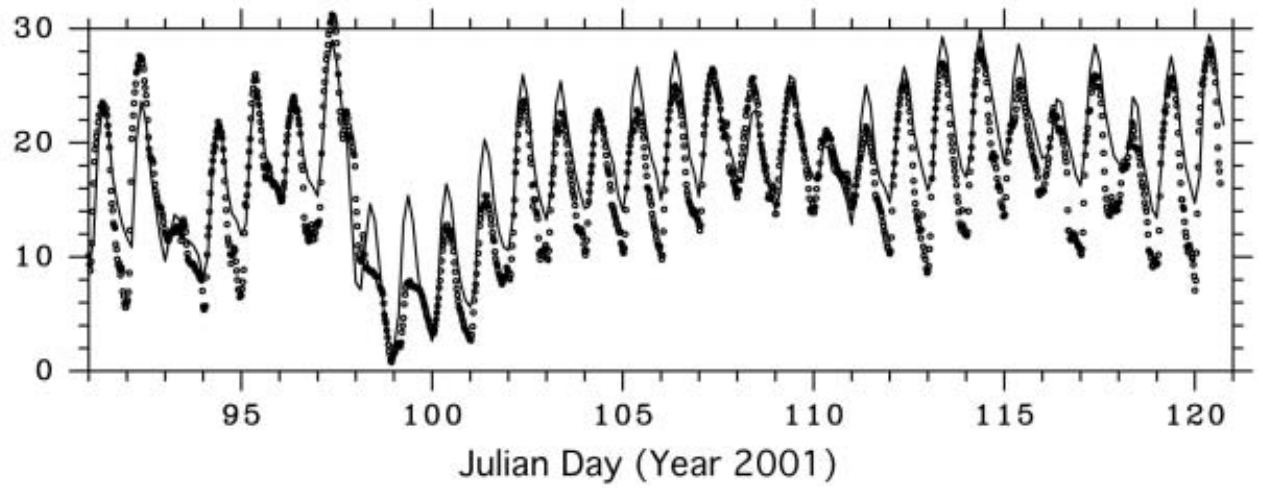

Fig. 4. Comparison with the ADEC Qira site. (a) wind speed at $3 \mathrm{~m}$ height, (b) wind direction, (c) surface downward short-wave radiation, $R_{s}$, and (d) air temperature at $2 \mathrm{~m}$ height. Lines are from model Experiment-G3. 
wind peak, the wind direction turned to an easterly wind. The wind speed given from Experiment-G3 is typically slightly stronger than that shown in Experiment-G2, possibly because of the resolution of the Tian Shan Mountains (Experiment-G3 resolves a strong wind pass within the mountains). This must be important for prediction of dust emissions. A detailed case study will be discussed in the next section.

Differences between Experiment-G3 and Experiment-G2 are generally small, except in the west and south regions. In the south region, the wind speed from Experiment-G3 is smaller than that from Experiment-G2 because of the roughness in the oasis city and the resolution of nearby high mountains. SYNOP observation frequently reports a calm wind speed. The reason remains unclear, but one reason might be the effect of the oasis roughness surrounding the SYNOP observation point, which is usually difficult to include in the mesoscale meteorological model.

More quantitative comparison is included in Table 3. It shows a comparison of average wind speed and the correlation coefficient in these stations. It should be pointed out that wind speed is reported with $1 \mathrm{~m} \mathrm{~s}^{-1}$ resolution and most of the SYNOP observation site is located in the oasis city. Therefore, the nighttime wind speed is quite frequently reported as calm. Because of low wind-speed resolution and frequently calm winds, the correlation coefficient $(r)$ ranges from $0.14-0.54$ in the Taklimakan region, even though the model represents the high wind peak correctly. The values of $r$ at Alar and Bachu are less than 0.2; this value is not statistically significant under the $F$-test (5\% level). The reason for such a low value of $r$ is not clarified in this study-more careful examination is necessary. All values of $r$ for other stations are statistically significant.

In other regions also, the RAMS wind field reproduces general trends very well. For Ejin $\mathrm{Qi}$, the RAMS wind field is excellent: the correlation coefficient there is 0.71 .

Calculated wind speeds at Qira site correlate well with measured values. However, the model does not adequately reproduce the very strong wind peaks at Jdays 93, 115, and 118. Except for these days, the model wind speed agreed very well; furthermore, it captured the diurnal change of wind direction (see Fig. 4b). The observed wind direction frequently showed a southerly wind, which can be considered as a local wind between the Qira site and the mountains, as reported by Mikami et al. (1995), but model results were not able to reflect this local south wind.

The short-wave radiation calculated by the model does not incorporate the attenuation effect of dust (no interaction of dust and radiation), but the calculated Rs reflect the major observed variation. Modeled Rs markedly overestimated Jdays 93, 98, 99, and 118. One reason for that over-prediction for Jdays 98 and 99 is the cloud cover. RAMS cloud prediction is generally good, but the exact location of clouds is usually very difficult to reproduce. Consequently, in Fig. 4c, two additional values (each point located at $50 \mathrm{~km}$ south and north from Qira) are plotted using dashed lines. Apparently, the observed Rs are within the error bar except for Jday 98, when Rs is highly attenuated by clouds. Figure 4c also shows that the model-calculated $\mathrm{Rs}$ is sometimes $100 \mathrm{~W} \mathrm{~m}^{-2}$ larger than that of the observed value on a fine day. These over-predictions are responsible for the over-prediction of surface air temperature (Fig. 4d). Another possibility, especially apparent for Jdays 93 and 98, is the Rs attenuation by heavy dust. Unfortunately, aerosol optical depth measurement was not conducted in the year 2001.

The basic model comparisons shown in this section confirm that the RAMS/CFORS model results reproduced an important meteorological condition during the major dust episode, especially the strong northerly wind by cold-front, and its related dust peak. In the next section, we will discuss a detailed case study of the passage of a cold front.

\subsection{Case study of a synoptic scale cold-front pass-over of the Tian Shan Mountains}

In this section, we will describe a case study of the response of the wind field in the Tarim Basin to a synoptic-scale cold-front based on ECMWF analysis, the RAMS model field, and SYNOP observation. As a typical example, a case study of $\mathrm{A}_{3}$, as shown in Fig. 2, was analyzed and compared. It includes the detailed wind-flow response within the Tarim Basin; especially the complicated local circulation will be 
(a) Jday 96 (April 6, 2001) 6UTC

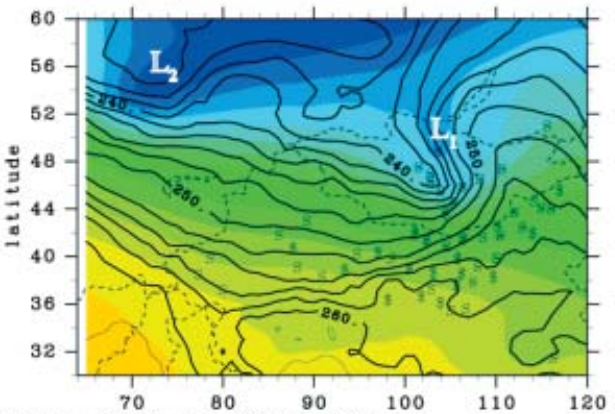

(b) Jday 97 (April 7, 2001) 6UTC

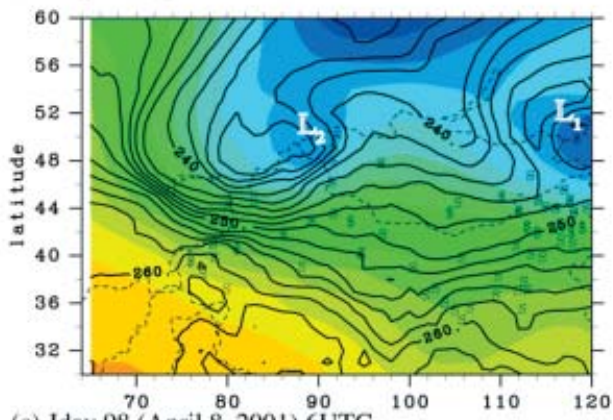

(c) Jday $98^{70}$ (April 8,2001$)$ 6UTC ${ }^{100}$

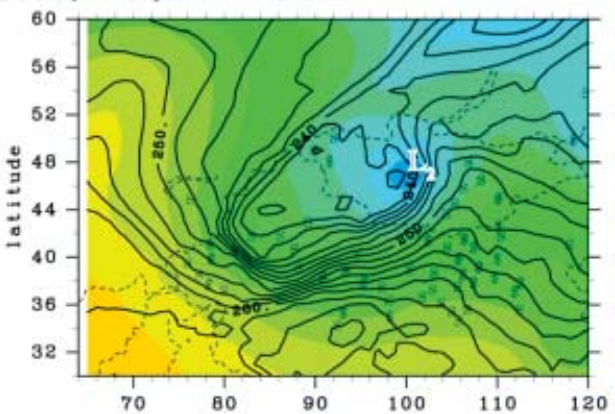

(d) Jday 99 (April 9, 2001) 6UTC

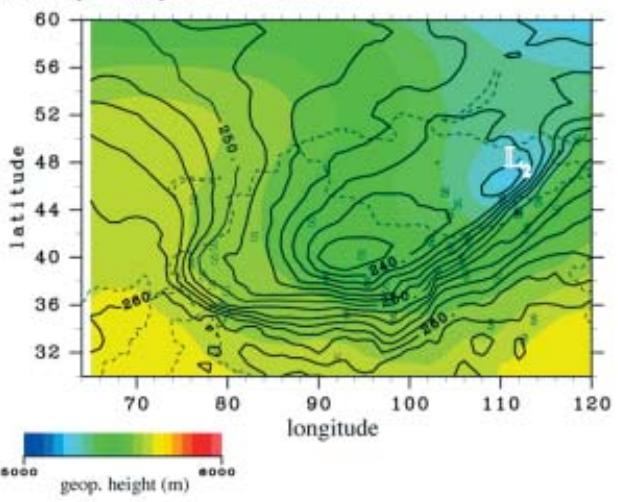

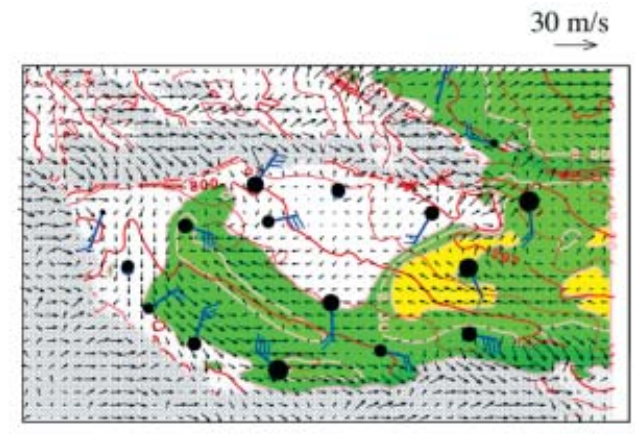
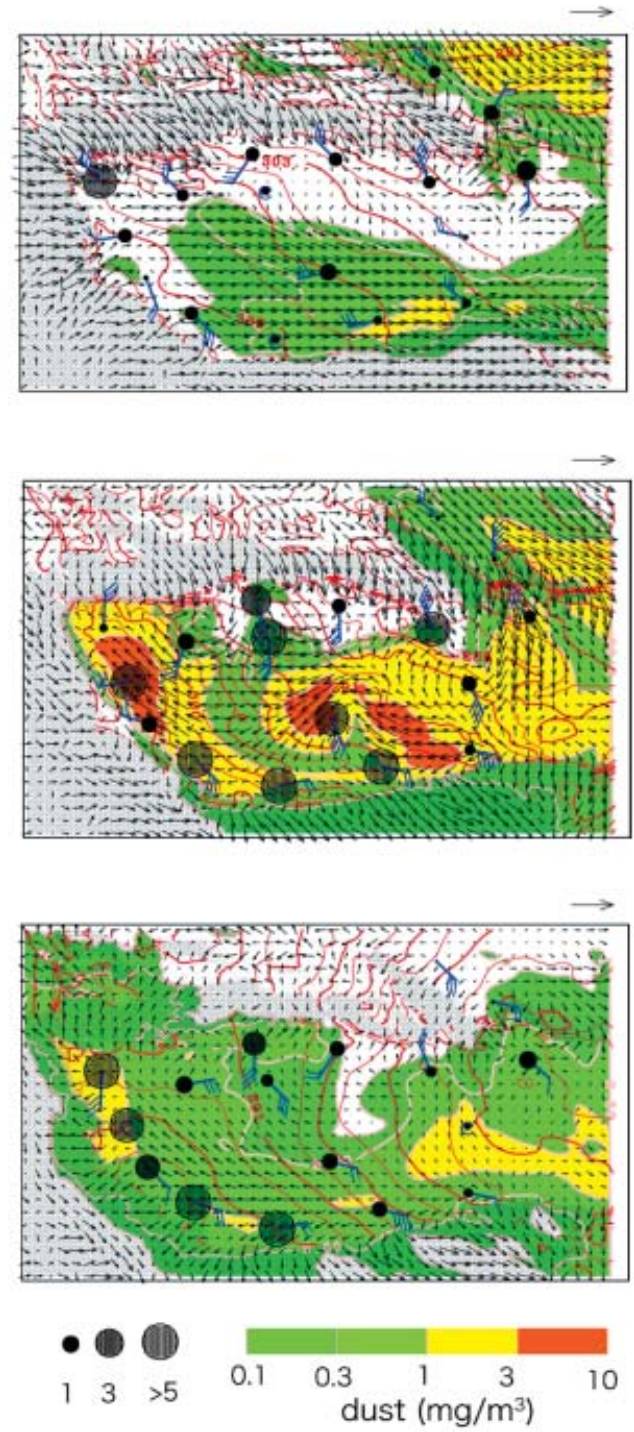

Fig. 5. Left column: geopotential height (color) and potential temperature (contour) at the $500 \mathrm{hPa}$ level from ECMWF global analysis data. Symbol $\$$ in the figure show dust signal from SYNOP observation.

Right column: the simulated surface level wind field with the potential temperature (K; contour) at $z=3000 \mathrm{~m}$ level and surface dust concentration (color in log scale). Wind barbs and solid circles show the SYNOP wind field and $C_{\text {TSP }}$, respectively. Topography $(z>2000 \mathrm{~m})$ is shaded by tone (Location of SYNOP site is shown in Fig. 1c). 
discussed. The selected period corresponds to the typical pattern of the Tian Shan Mountain pass-over, as indicated by Aoki (2003).

Figure 5 shows the synoptic scale analysis and RAMS simulation results for Case $A_{3}$ (Jdays 96, 97, 98, and 99 at 6 UTC). The left column of the figure shows the geopotential height (color) and potential temperature (contour) at the $500 \mathrm{hPa}$ level from ECMWF global analysis data. Symbol $\$$ in the figure indicates the dust phenomena observed in the SYNOP observation site (not related to the dust concentration level). In this figure, the dashed line indicates the national border; the location of $L$ is determined by the geopotential height contour. The right column of the figure shows the simulated surface level wind field with the potential temperature (red contour) at the $z=3000 \mathrm{~m}$ level (above sea level; ASL) and surface dust concentration (color in log scale color). The SYNOP wind field is shown by wind barbs and $C_{\text {TSP }}$ is indicated by the size of solid circles. Shading represents topography $(z>2000 \mathrm{~m})$; the geographical location of the SYNOP site is identical to that in Fig. 1c.

Figure 6 shows the vertical $\mathrm{Y}$ cross section along the Tazhong site (NS line in Fig. 1c) for Jdays 96-98. In this figure, the terrain following RAMS/CFORS vertical coordinate is transformed to the Cartesian coordinate level and the stipple region represents the model topography. It shows the wind vectors ( $\mathrm{v}$ and $\mathrm{w}$ ), potential temperature (contour), and dust concentrations (tone). The vertical cross section was taken using polar stereographic $\mathrm{Y}$ coordinates (not true south-north). The vertical velocity is scaled for better viewing.

Episode $\mathrm{A}_{3}$ was remarkable. We observed two large sequential low-pressure systems (identified as $L_{1}$ and $L_{2}$ in Fig. 5) sweep over both the Taklimakan and Gobi Deserts. These low-temperature troughs hit both the Taklimakan and Gobi regions. A weak temperature trough passed through the regions on Jday 94 (4 April), but only slightly dusty conditions were reported in the Taklimakan (not shown in Figure). A developing low $L_{1}$ appeared on Jday 95 (5 April) over the western edge of the Mongolian border; it arrived over the central part of Mongolia on Jday 96 (6 April). A large number of dust phenomena were reported over the Loess Plateau, Inner Mongolia, the Gobi
Desert, and Mongolia. Dust emitted in this episode was transported to the east along the coldfront line; it arrived in the region of Eastern Mongolia-Northeastern China on Jday 97 (7 April). This $L_{1}$ moved to the east at high latitudes $\left(\right.$ ca. $40^{\circ} \mathrm{N}$ ) and was responsible for the strong wind at $\mathrm{A}_{2}$ (Fig. 2a). The second large low $L_{2}$ appeared on Jday 97 (7 April) at almost the same location as $L_{1} . L_{2}$ took almost the same route as $L_{1}$ and moved to the east. It passed over the Taklimakan region on 8 April and the Gobi region on Jdays 98-99 (8-9 April). Many dust reports occurred just between $L_{1}$ and $L_{2}$.

Next we will examine the complicated airflow within the Tarim Basin before and after the passage of low $L_{2}$. On April 6 (Fig. 5a, right panel), the west-south region of the basin showed a NW wind whereas the east to central part of the basin showed an easterly wind. SYNOP wind reported a relatively weak wind. The simulated maximum dust concentration was $1.2 \mathrm{mg} \mathrm{m}^{-3}$ at the west side of Tikanlik. On 7 April (Fig. 5b), a strong NW wind zone appeared over the Pamir Plateau and the Tian Shan Mountains. However, it did not penetrate into the basin. Wind flow within the basin showed a westerly flow and dust concentration increased at the SE edge of the basin. A steep trough attributable to the low $L_{2}$ passed over the Tian Shan Mountains around 12 UTC of 7 April (not shown in Fig. 5). After the passage of $L_{2}$, airflow within the basin differed completely from that of 7 April (as shown in Fig. 5c), and illustrated the dominance of easterly flow in the basin. A strong easterly wind from the east side of the Tarim Basin was especially obvious. Dust concentration from the CFORS model showed zones of high concentration (ca. $4 \mathrm{mg} \mathrm{m}^{-3}$ ) between Tazhong-Qiemo and Pishan-Kashi. The horizontal gradient of potential temperature at $z=3000 \mathrm{~m}$ was the steepest on this day because of the penetration of the cold air mass (Fig. 5c). On 9 April, the cold front had already passed away from the Tarim Basin. Airflow in the basin showed an easterly wind, but the wind speed was lower than that of 8 April.

This case study clearly indicates that the wind flow within the Tarim Basin quickly affects the passage of the cold trough and turns the wind direction from westerly to easterly; 

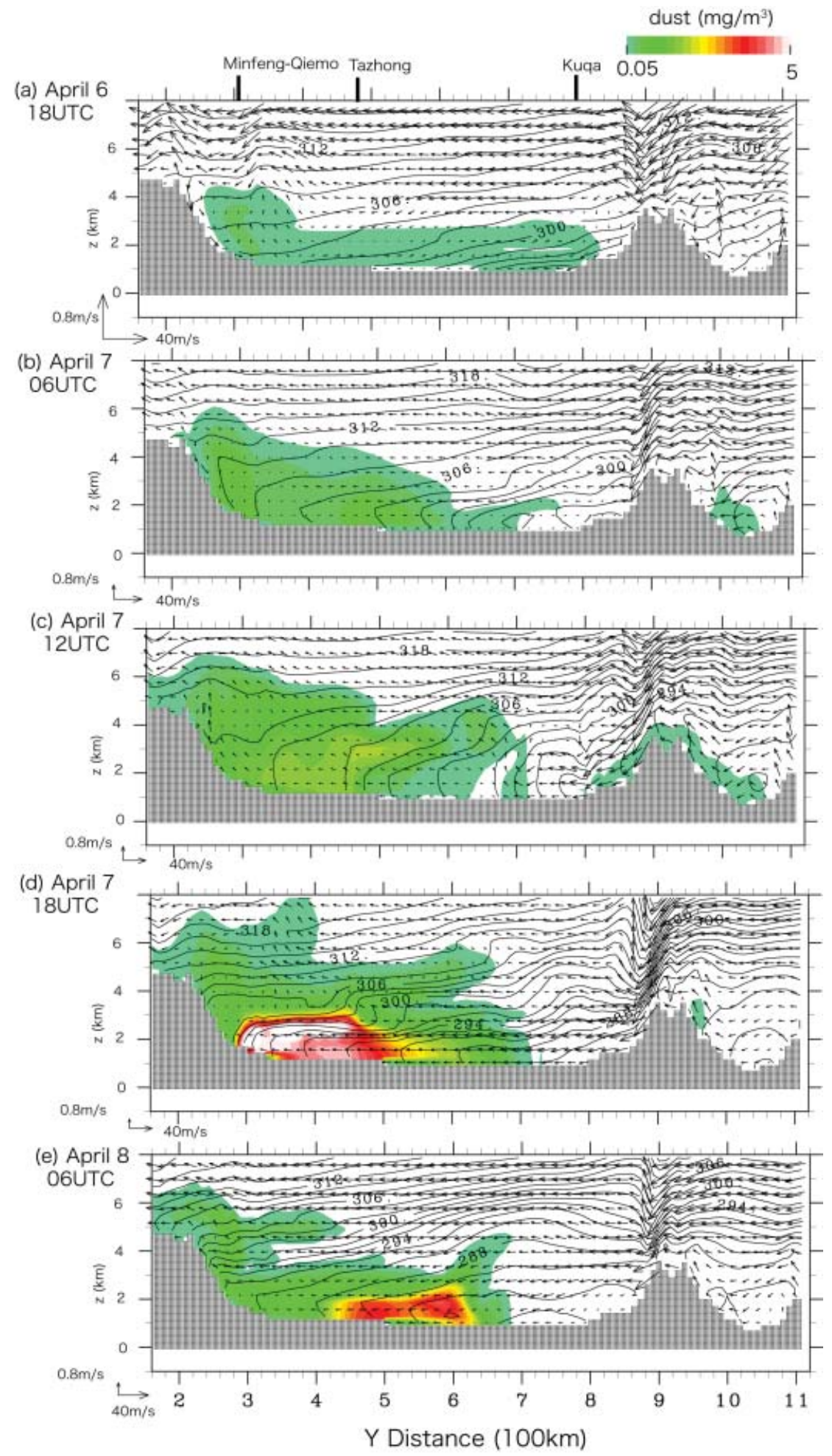

Fig. 6. Vertical Y cross section along the Tazhong site from Jday 96 to 98. It shows the wind vectors ( $\mathrm{v}$ and $\mathrm{w}$ ), potential temperature (K: contour) and dust concentration (tone). The vertical velocity is scaled as shown in wind scale. 
this resultant easterly wind facilitates dust emissions and transport over the Taklimakan Desert. Wind flow within the basin is relatively complex, but RAMS wind flow generally shows good agreement with observations.

One important meteorological condition shown in Fig. 6 is the spatial distribution of potential temperature within the Tarim Basin. The potential temperature profile shown in Fig. $6 \mathrm{a}$ is determined mainly by the synoptic scale meteorology, which shows a north-south gradient within the Tarim Basin. On 7 April, 6 UTC, the penetration of cold air mass started slightly from the top of the Tian Shan Mountains (Fig. 6c). We can see that the cold air by $L_{2}$ is located at the northern side of the Tian Shan Mountains (Figs. 6b-6d), whereas the vertical gradient of potential temperature at the south side took an isothermal profile (Fig. 6b). The main body of cold air penetration was simulated around 12 UTC (Fig. 6c) and the strong down-slope wind exceeding $30 \mathrm{~m} \mathrm{~s}^{-1}$ was simulated aloft. The necessary time to sweep out of the basin from the north to the south side was less than $12 \mathrm{~h}$ in this case. High concentration of the dust zone was formed within the head of the cold flow; it swept out of the Tarim Basin very quickly: the line of $296 \mathrm{~K}$ visibly traverses the Basin within $6 \mathrm{~h}$ (Figs. 6c and 6d). The thickness of this dense dust layer is approximately $1500 \mathrm{~m}$. After this sweep out, the eastern wind brought high dust concentration in areas near Tazhong (Fig. 6e).

\subsection{Composite analysis of the average structure of wind flow in the Tarim Basin}

The average wind structure, seen when the easterly wind appears in Tazhong, is another important point of investigation. Figure $2 \mathrm{a}$ shows that the easterly flow is quite frequently simulated in the eastern part of the Taklimakan area. Therefore, composite analysis was made when the easterly wind was simulated at Tazhong, under the condition that the WD is between NE-SE, and that WS > $4 \mathrm{~m} \mathrm{~s}^{-1}$ at the first vertical model grid. This condition occurred $48 \%$ of the time during simulations.

Figure 7 shows the result of the composite analysis. Figures $7 \mathrm{a}$ and $7 \mathrm{~b}$ respectively show horizontal wind flow and dust concentration at the surface and $z=3000 \mathrm{~m}$. Figure $7 \mathrm{a}$ also includes the SYNOP wind barbs, and Fig. 7b includes the potential temperature at $z=$ $3000 \mathrm{~m}$ (dashed contour) and dust concentration ratio between $z=3000 \mathrm{~m}$ and surface (solid contour). Figures $7 \mathrm{c}$ and $7 \mathrm{~d}$ respectively show the vertical cross-section along the Tazhong for $\mathrm{Y}$ and $\mathrm{X}$ sections. They include the WD (color), WS (purple contour), dust concentration (black dashed contour), and potential temperature (green contour).

Figure 7 shows that the dust concentration is strongly related with the spread of the easterly wind zone. We can also view a highconcentration zone (exceeding $200 \mu \mathrm{g} / \mathrm{m}^{3}$ ) extending to higher altitudes $(z>3000 \mathrm{~m})$ at the Basin's southern and western edges. Figure $7 \mathrm{~b}$ shows the concentration ratio between $z=3000 \mathrm{~m}$; its ratio is greater than unity at the southern and western sides of the Basin, while it is only 0.5 over Tikanlik and Tazhong. This indicates that the relatively shallow dust layer from the eastern side of the Taklimakan Desert is transported to the south and western parts. During this transport process, the dust layer becomes thicker and tends to produce a uniform concentration profile. Such a vertical dust structure is important for penetration of PBL dust into the free atmosphere and for its long-range transport to Korea and Japan.

The easterly wind zone is $2 \mathrm{~km}$ in thickness and horizontally $400 \mathrm{~km}$ in the $\mathrm{Y}$ direction and $1000 \mathrm{~km}$ in the $\mathrm{X}$ direction (Figs. 7c and 7d). Wind speed has its peak within this easterly zone $\left(>8 \mathrm{~m} \mathrm{~s}^{-1}\right)$. The potential temperature contour in the $\mathrm{Y}$ section shows the slanting structure from the Tian Shan Mountains to the southern foot of the Kunlun Mountains (Minfeng). The potential temperature level of $300 \mathrm{~K}$ over the Tian Shan Mountain hits the desert surface (descending $2000 \mathrm{~m}$ ) at the $400-\mathrm{km}$ south point. This rate of descent is more gentle than that shown in Fig. 6 because Figs. 7c and $7 \mathrm{~d}$ depict results of composite analysis, whereas Fig. 6 is a snapshot during the extreme episode. The vertical potential temperature gradient is weaker in the southern part of the Tarim Basin than in the northern part. In the $\mathrm{X}$ direction, thermal stratification is stronger in the eastern side of the Basin. At the west side of the Basin, the vertical potential temperature gradient is ca. $0.2-0.3 \mathrm{~K} /$ 
(a) suface wind (easterly case) and dust concentration

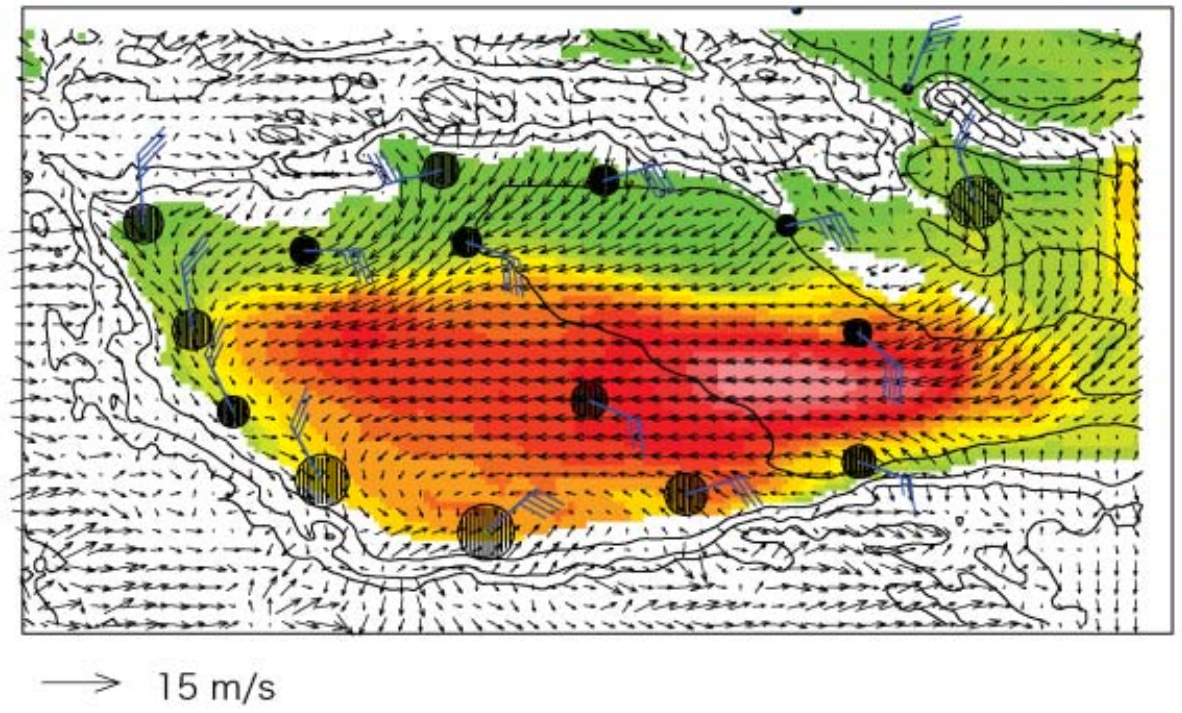

(b) wind, dust and potential temperature at $\mathrm{z}=3000 \mathrm{~m}$

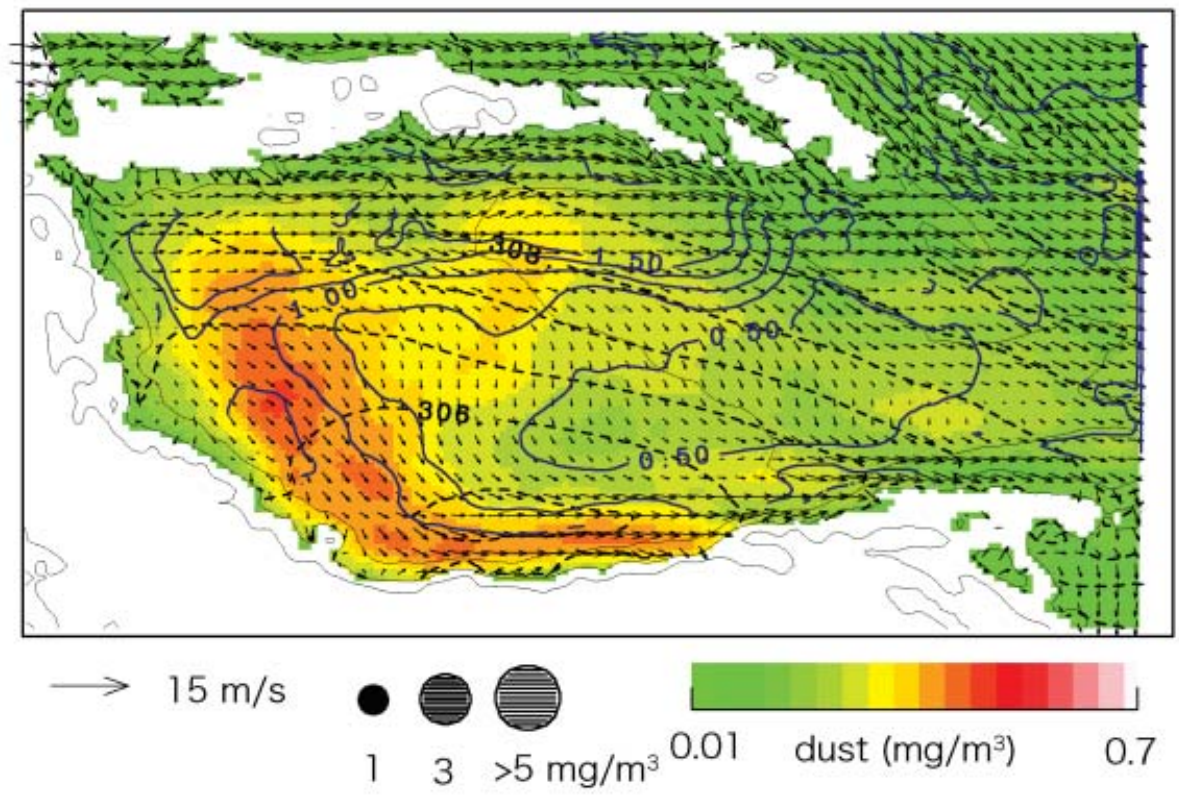

Fig. 7. Result of composite analysis of the easterly wind case. (a) and (b) show the horizontal wind flow and dust concentration at the surface and $z=3000 \mathrm{~m}$, respectively. (a) also includes the SYNOP wind barbs and SYNOP $C_{\text {TSP }}$ by the sizes of the solid circles, and (b) includes the potential temperature at $z=3000 \mathrm{~m}$ (dashed contour) and dust concentration ratio between $z=3000 \mathrm{~m}$ and surface (K; contour). (c) and (d) show the vertical cross-section along the Tazhong for Y and X section, respectively. It includes the WD (deg; color), WS ( $\mathrm{m} \mathrm{s}^{-1}$; white contour), dust concentration $\left(\mu \mathrm{g} / \mathrm{m}^{3}\right.$ : black dashed contour) and potential temperature (K: green contour). 
(c) $Y$ cross section along the Tazhong

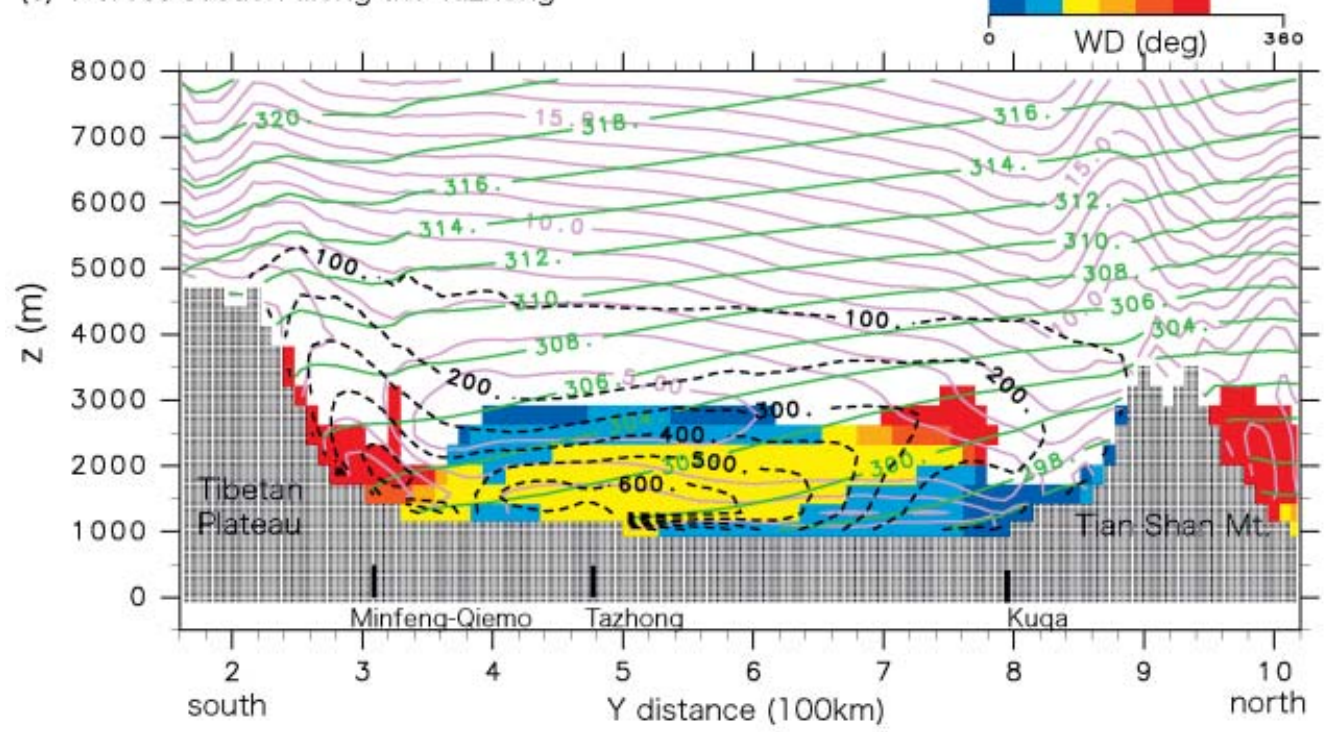

(d) $\mathrm{X}$ cross section along the Tazhong

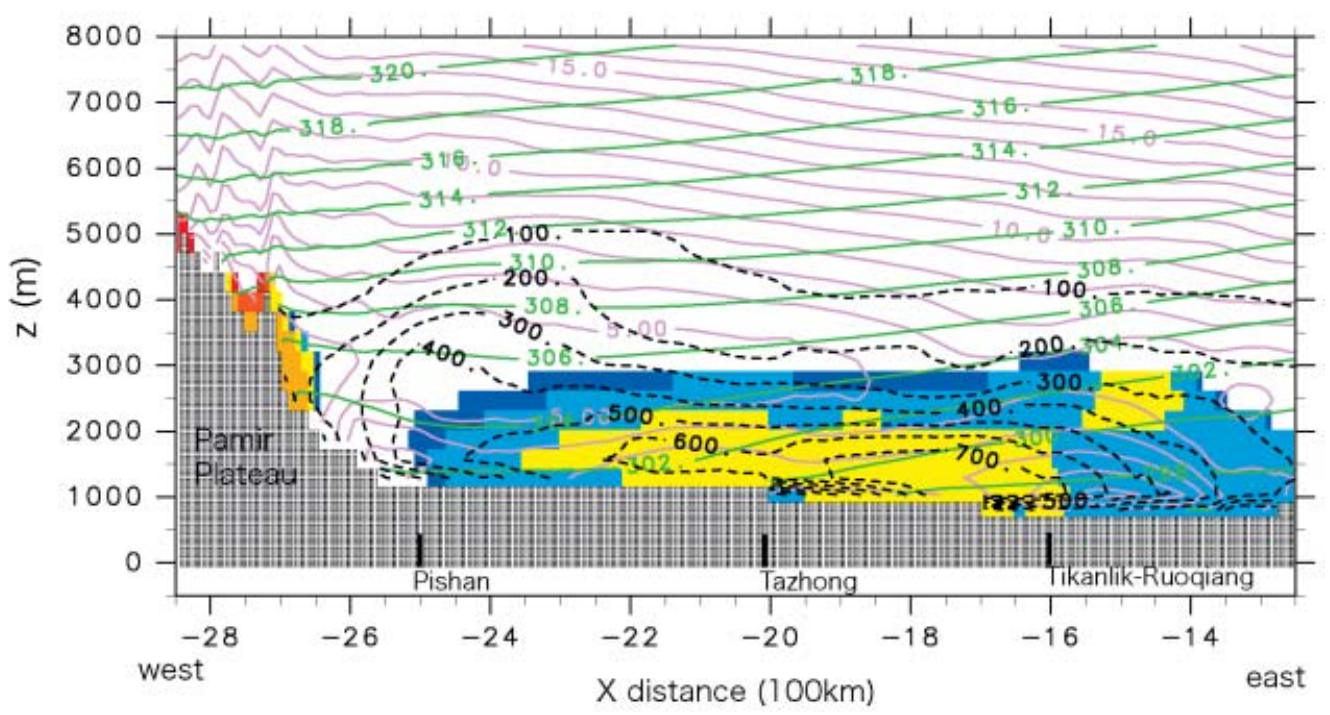

Fig. 7 (continued)

(100 m). Therefore, atmospheric stratification is stronger (more stable) in the northern and eastern parts of the Basin (i.e., colder areas) and weakly stable in the southern and western parts of the Basin (warmer areas). The horizontal gradient of the potential temperature results from the cold air blocking effect of the Pamir Plateau and Tian Shan Mountains; the cold air makes a detour around the mountains and penetrates into the basin from the open eastern side. Furthermore, the air mass passing over the Tian Shan Mountains becomes warmer during the dry adiabatic descending process and reaches the southern side of the basin. This weak potential temperature gradient and strong wind shear between the boundary layer and free atmosphere functions to efficiently mix the dust vertically.

\subsection{Characteristics of simulated dust distribution over the Tarim Basin}

Next, we analyze characteristics of dust distribution within the Tarim Basin based on the SYNOP $C_{\mathrm{TSP}}$ and RAMS/CFORS model re- 
(a) Tarim East Side

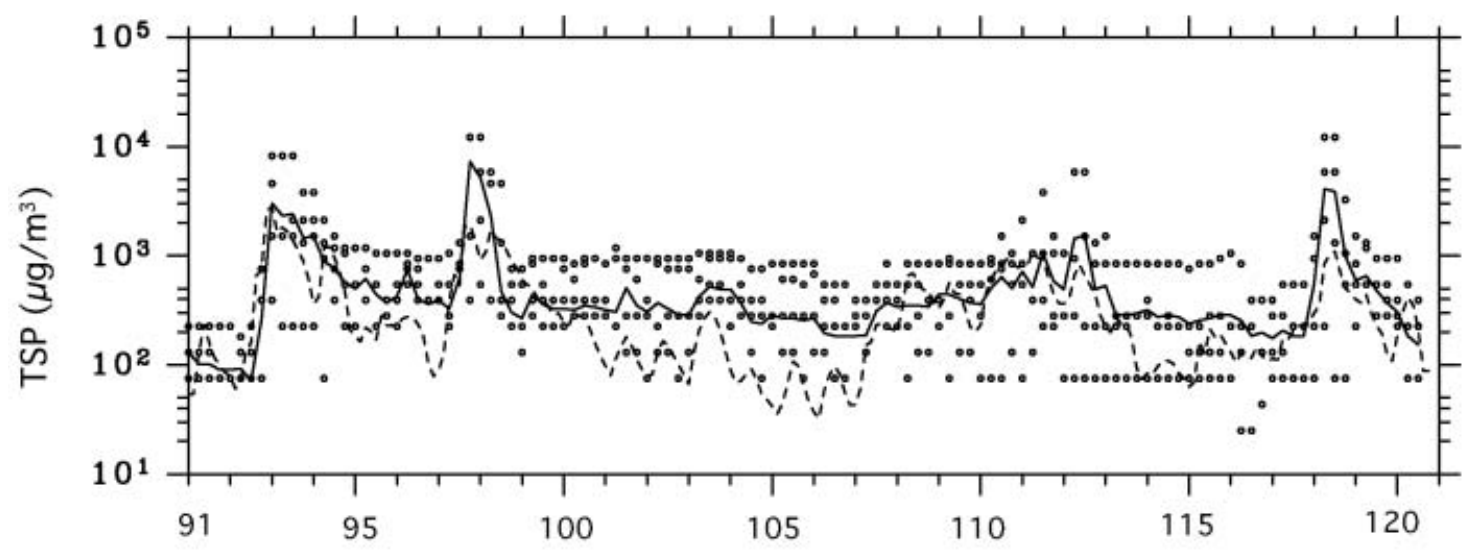

(b) Tarim West Side

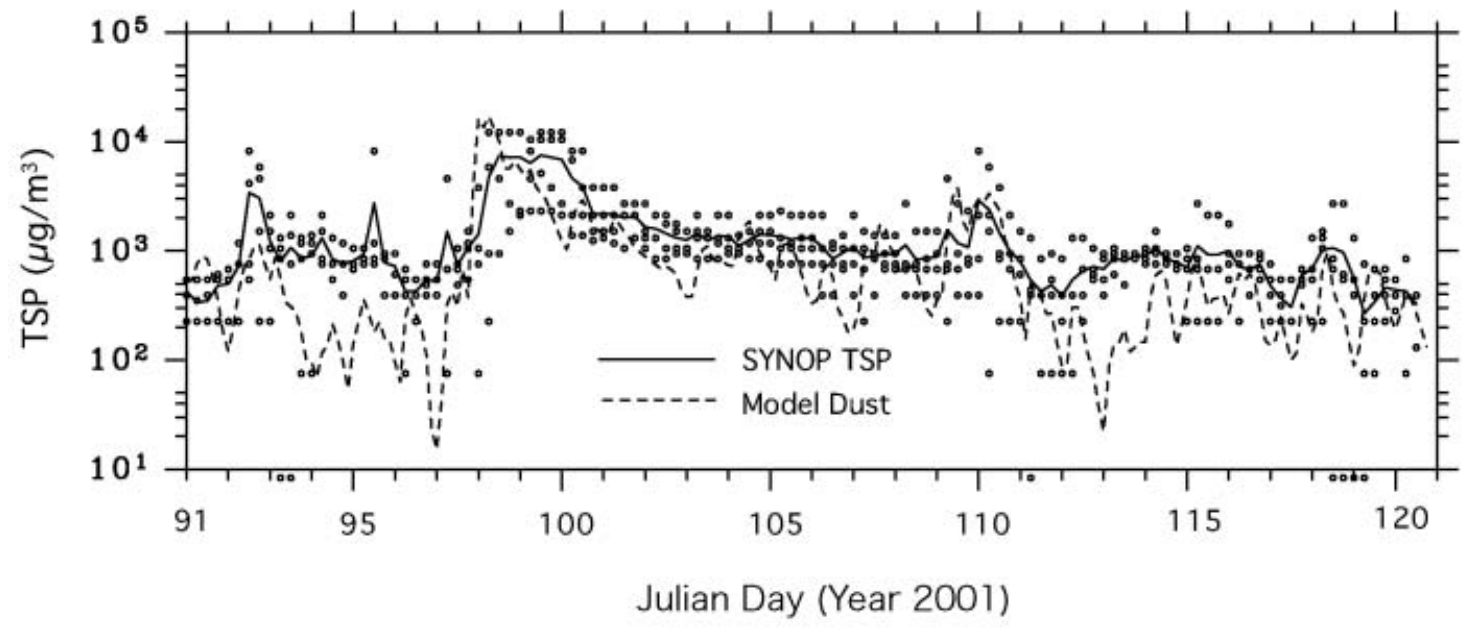

Fig. 8. Comparison of SYNOP $C_{\text {TSP }}$ and RAMS/CFORS model averaged over the (a) eastern and (b) western 4 SYNOP sites.

sults. SYNOP $C_{\mathrm{TSP}}$ in each station is sometimes widely scattered and therefore difficult to assign an absolute concentration level, so an analysis was made to retrieve the average characteristics of the eastern and western sides of the Tarim Basin. For averaging the values for the east side of the Basin, the respective visibilities at the four SYNOP stations (Tazhong, Tikanlik, Ruoqiang, and Qiemo) were converted to $C_{\mathrm{TSP}}$. Then mean values were used for comparison. For the west side, data from four stations (Kashi, Sache, Pishan, and Hotan) were used. Model results were also averaged surrounding the region of these SYNOP stations. Figure 8 shows results of the comparison for April 2001. Note that model dust concentration data for the west part of the Basin (Fig. $8 b$ ) are scaled by a factor of five because the concentration level is different.

Good correlation was found between $C_{\mathrm{TSP}}$ and RAMS/CFORS dust concentration. The range of $C_{\mathrm{TSP}}$ is shown by symbols. Although that range is wide, it shows the important dust onset peaks on Jdays 93, 98, 112, and 118. Model dust concentration reproduces the observed major time variation. Model dust con- 
centration shows the respective increases of Jdays 98 and 118 well.

For the western part of the Tarim Basin, scaled model dust concentrations show excellent agreement with SYNOP $C_{\mathrm{TSP}}$, but it is noteworthy that the model dust concentration is greatly under-estimated compared with the observation, even though the model dust perfectly reproduces the observed time variation. The average value of visibility base $C_{\mathrm{TSP}}$ for the western side is 2.3 times higher than that for the eastern side, whereas it was the other way around in the CFORS model: the western side was 0.6 times that of the eastern side. One reason for this observed high dust concentration on the west side is the contribution of frequent 'suspended dust' reports (Kurosaki and Mikami 2002) even at low surface-wind velocities. The current dust emission scheme relies heavily upon high wind speeds (such as cold air outbreak). However, this scheme is insufficient to simulate dust phenomena in the western part of the Tarim Basin. In this region, largescale suspended dust and dust plume phenomena generated by thermal convection (i.e., dust devil) must play an important role in the background level of dust concentration. Therefore, further improvement of the dust emission scheme must be undertaken as the next step of model application (e.g., Shao and Wang 2003).

\section{Conclusions}

A nesting RAMS/CFORS regional meteorology/dust-transport model was applied to an Asian region including the Taklimakan Desert. A triple-grid system with resolutions of $81 \mathrm{~km}$, $27 \mathrm{~km}$ and $9 \mathrm{~km}$ was designed and model calculation was conducted for April 2001 to examine typical springtime meteorology and dust episodes. The model performance was examined based on the meteorological observation at WMO SYNOP station surrounding the Taklimakan Desert and ADEC special observation site at Qira. We found the following:

(1) The model results reproduced complicated airflows within the Tarim Basin, strong down slope wind from the Tianshan Mountains when the meteorological disturbance cross over the Taklimakan region, and strong easterly flow from the Hexi Corridor side. A detailed case study of 6 April-9
April, when a huge cold front passed over the Taklimakan Desert, was studied. Results verified that the RAMS/CFORS model successfully simulated the complicated local wind variation within the Tarim Basin.

(2) We found that a strong, $2-\mathrm{km}$ high easterly wind was frequently simulated; it shows a strong correlation with dust emissions. Composite analysis when the Tazhong site simulated an easterly wind was conducted. It showed that the percentage of the occurrence of this condition was ca. $50 \%$ of the full simulation period. The scale of the easterly wind zone is $400 \mathrm{~km}$ in the $\mathrm{Y}$ direction, $1000 \mathrm{~km}$ in the $\mathrm{X}$ direction and 2$3 \mathrm{~km}$ vertically. Simulated high dust concentration shows a good correlation with this easterly wind zone. We also found that atmospheric stratification is stronger (more stable) in the northern and eastern parts of the basin (colder areas) but weakly stable in the southern and western parts of the basin (warmer areas). This condition and strong wind shear are very important for efficient vertical mixing of PBL dust into the free atmosphere.

(3) Averaged model dust concentration fields were analyzed and the averaged surface concentration ratio was ca. 0.6 between the eastern and western sides of the Tarim Ba$\sin$ (the eastern side is higher than western side). However, this modeled ratio showed an opposite relation with the SYNOP visibility. The low visibility at the western side of the Taklimakan Desert can be considered mainly as 'suspended dust' (Kurosaki and Mikami 2003), indicating that the current high wind type dust emission scheme may not be sufficient to simulate dust phenomena in the western Tarim Basin. Further improvement of the dust emission scheme during the weak wind condition must be developed for the next step of model application.

This study mainly focuses on the capability of nesting RAMS/CFORS model and its evaluation. As discussed in many dust modeling studies, dust-modeling schemes engender many uncertainties that are inherent in data for dust particle distribution, land use and soil texture information, saltation/dust emission schemes, 
and other data. Therefore, more closely related studies of the measurement groups are required. Continued research, including detailed measurement data from ADEC activities and quantitative dust budget analyses of the Taklimakan dust and their exchange processes between the PBL and the free atmosphere, must be addressed for the next step of modeling studies.

\section{Acknowledgements}

This work was performed through the project work of Aeolian Dust Experiment on Climate impact (ADEC) supported by the Ministry of Education, Culture, Sports, Science and Technology of Japan. This work is also partly supported by Core Research for Evolution Science and Technology (CREST) of Japan Science and Technology Corporation (JST) and Steel Industry Foundation for Advancement of Environmental Protection Technology. AWS observation data at the Qira site were provided by Dr. M. Mikami of the Meteorological Research Institute of Japan. The authors want to acknowledge the Chinese Meteorological Agency (CMA) for preparation of the SYNOP data set used in this study.

\section{References}

Aoki, I. The process of dust storm generation in Tarim Basin, Northwest China, Master Thesis of Institute of Geoscience, Tsukuba University, 2003 January (in Japanese).

Cotton, W.R., R.A. Pielke, R.L. Walko et al., 2003: RAMS 2001: Current status and future directions, Meteorol. Atmos. Phys., 82, 5-29.

Gong, S.L., X.Y. Zhang, T.L. Zhao, I.G. McKendry, D.A. Jaffe, and N.M. Lu, 2003: Characterization of soil dust aerosol in China and its transport and distribution during 2001 ACEAsia: Part 2 Model simulation and validation, J. Geophys. Res., 108, 4262, doi:10.1029/ 2002JD002633.

Iwasaka, Y., G.-Y. Shi, M. Yamada, A. Matsuki, D. Trochkine, Y.S. Kim, D. Zhang, T. Nagatani, T. Shibara, M. Nagatani, H. Nakata, Z. Shen, G. Li, and B. Chen, 2003: Importance of dust particles in the free troposphere over the Taklimakan Desert: Electron microscopic experiments of particles collected with balloon-borne particle impactor at DunHuang, China, J. Geophys. Res., 108, 8644, doi:10.1029/ 2002JD003270.
Kai, K., Y. Okada, O. Uchino, I. Tabata, H. Nakamura, T. Takasugi, and Y. Nikaidou, 1988: Lidar Observation of a Kosa (Asian dust) over Tsukuba, Japan during the Spring of 1986, J. Meteorol. Soc. Jpn., 66, 457-472.

Kurosaki, Y. and M. Mikami, 2002: Seasonal and regional characteristics of dust event in the Taklimakan Desert, J. Arid Land Studies, 11, 245-252.

- and M. Mikami, 2003: Recent frequent dust events and their relation to surface wind in East Asia, Geophys. Res. Lett., 30, 1736, doi:10.1029/2003GL01726.

Liu, M. and D.L. Westphal, 2001: A study of the sensitivity of simulated dust production to model resolution, J. Geophys. Res., 106, 18009-18112.

—, D.L. Westphal, S. Wang, A. Shimizu, N. Sugimoto, J. Zhou, and Y. Chen, 2003: A highresolution numerical study of the Asian dust storms on April 2001, J. Geophys. Res., 108, 8653, doi:10.1029/2002JD003178.

Mikami, M., 1997: Dust storm observed in the southern edge of Taklimakan Desert, J. Arid Land Studies, 7, 97-106.

-, T. Fujitani, and X. Zhang, 1995: Basic characteristic of meteorological elements and observed local wind circulation in Taklimakan Desert, China, J. Meteorol. Soc., Japan, 73, 899-908.

, O. Abe, M. Du, O. Chiba, K. Fujita, M. Hayashi, Y. Iwasaka, K. Kai, K. Masuda, T. Nagai, T. Ootomo, J. Suzuki, A. Uchiyama, S. Yabuki, Y. Yamada, M. Yasui, G. Shi, X. Zhang, Z. Shen, W. Wei, J. Zhou, 2002: The Impact of Aeolian Dust in Climate: Sino-Japanese Cooperative Project ADEC, J. Arid Land Studies, 11, 211-222.

, Y. Yamada, M. Ishizuka, T. Ishimaru, W. Gao, and F.J. Zeng, 2004: Measurement of saltation process over Gobi and sand dune in the Taklimakan Desert China using newly developed Sand Particle Counter, J. Geophys. Res. (in press).

Park, S.U. and H.-J. In, 2003: Parameterization of dust emission for the simulation of the Yellow Sand (Asian dust) event observed in March 2002 in Korea, J. Geophys. Res., 108, 4618, doi:10.1029/2003JD003484.

Pielke, R.A., W.R. Cotton, R.L. Walko, C.J. Tremback, W.A. Lyons, L.D. Grasso, M.E. Nicholls, M.D. Moran, D.A. Wesley, T.J. Lee, and J.H. Copeland, 1992: A comprehensive meteorological modeling system-RAMS, Meteorol. Atmos. Phys., 49, 69-91.

Satake, S., I. Uno, T. Takemura, G.R. Carmichael, D. Streets, N. Sugimoto, A. Shimizu, and M. Ue- 
matsu, 2004: Characteristics of Asia aerosols transport simulated with the regional scale chemical transport modeling during the ACEAsia period, J. Geophys. Res., 109, D19S22 doi:10.1029/2003JD003997.

Shao, Y., Y. Yang, J. Wang, Z. Song, L.M. Lesile, C. Dong, Z. Zhang, Z. Lin, Y. Kanai, S. Yabuki, and Y. Chun, 2003: Northeast Asian dust storms: Real-time numerical prediction and validation, J. Geophys. Res., 108, 4691, doi:10.1029/2003JD003667.

_ and J. Wang, 2003: A climatology of Northeast Asian dust events, Meteorologische Zeitschrift, 12, 187-196.

Sun, J., M. Zhang, and T. Liu, 2001: Spatial and temporal characteristics of dust storms in China and its surrounding regions, 1960-1999: Relations to source area and climate, J. Geophys. Res., 106, 10325-10333.

Uno, I., H. Amano, S. Emori, K. Kinoshita, I. Matsui, and N. Sugimoto, 2001: Trans-Pacific Yellow Sand Transport observed in April 1998: Numerical Simulation, J. Geophys. Res., 106, 18331-18344.
, G.R. Carmichael, D.G. Streets, Y. Tang, J.J. Yienger, S. Satake, Z. Wang, Jung-Hun Woo, S. Guttikunda, M. Uematsu, K. Matsumoto, H. Tanimoto, K. Yoshioka, and T. Iida, 2003: Regional Chemical Weather Forecasting System CFORS: Model Descriptions and Analysis of Surface Observations at Japanese Island Stations During the ACE-Asia Experiment, $J$. Geophys. Res., 108, 8668 doi:10.1029/ 2002JD002845.

S. Satake, G.R. Carmichael, Y. Tang, Z Wang, T. Takemura, N. Sugimoto, A. Shimizu, T. Murayama, T. Cahill, S. Cliff, M. Uematsu, S. Ohta, P. Quinn, and T. Bates, 2004: Numerical Study of Asian Dust Transport during the Springtime of 2001 simulated with the CFORS model, J. Geophys. Res., 109, D19S24 doi:10.1029/2003JD004222.

Wang, Z., H. Ueda, M. Huang, 2000: A deflation module for use in modeling long-range transport of yellow sand over East Asia, J. Geophys. Res., 105, 26947-26960. 